CÁSSIA YUMI IKUTA

Comparação entre meios de cultura e condições de incubação para o primo isolamento de Mycobacterium bovis de bovinos brasileiros 


\section{Comparação entre meios de cultura e condições de incubação para o primo isolamento de Mycobacterium bovis de bovinos brasileiros}

Dissertação apresentada ao Programa de PósGraduação em Epidemiologia Experimental e Aplicada às Zoonoses da Faculdade de Medicina Veterinária e Zootecnia da Universidade de São Paulo para obtenção do título de Mestre em Ciências

\section{Departamento:}

Medicina Veterinária Preventiva e Saúde Animal

Área de concentração:

Epidemiologia Experimental e Aplicada às Zoonoses

\section{Orientador:}

Prof. Dr. José Soares Ferreira Neto 
Autorizo a reprodução parcial ou total desta obra, para fins acadêmicos, desde que citada a fonte.

DADOS INTERNACIONAIS DE CATALOGAÇÃO-NA-PUBLICAÇÃO

(Biblioteca Virginie Buff D’ápice da Faculdade de Medicina Veterinária e Zootecnia da Universidade de São Paulo)

T.2441

FMVZ

Ikuta, Cássia Yumi

Comparação entre meios de cultura e condições de incubação para o primo isolamento de Mycobacterium bovis de bovinos brasileiros / Cássia Yumi Ikuta. -2011.

$77 \mathrm{f}$ : : il.

Dissertação (Mestrado) - Universidade de São Paulo. Faculdade de Medicina Veterinária e Zootecnia. Departamento de Medicina Veterinária Preventiva e Saúde Animal, São Paulo, 2011.

Programa de Pós-Graduação: Epidemiologia Experimental Aplicada às Zoonoses. Área de concentração: Epidemiologia Experimental Aplicada às Zoonoses.

Orientador: Prof. Dr. José Soares Ferreira Neto.

1. Primo isolamento. 2. Tuberculose bovina. 3. Mycobacterium bovis, 4. Meios de cultura. 5. Condições de incubação. 1. Título. 


\section{CERTIFICADO}

Certificamos que o Projeto intitulado "Influencia de dióxido de carbono no primo isolamento de Mycobacterium bovis.", protocolado sob o $n^{\circ} 1628 / 2009$, não utilizando animais, sob a responsabilidade do Prof. Dr. José Soares Ferreira Neto, está de acordo com os princípios éticos de experimentação animal da Comissão de Bioética da Faculdade de Medicina Veterinária e Zootecnia da Universidade de São Paulo e foi aprovado em reunião de 20/05/09.

We certify that the Research "Influence of carbon dioxide on the primary isolation of Mycobacteirum bovis", protocol number 1628/2009, under the Prof. Dr. José Soares Ferreira Neto, agree with Ethical Principles in Animal Research adopted by Bioethic Commission of the School of Veterinary Medicine and Animal Science of University of São Paulo and was approved in the meeting of day $05 / 20 / 09$.

São Paulo, 21 de maio de 2009

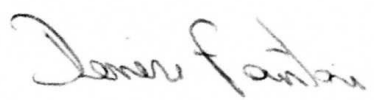

Profa Dra Denise Tabacchi Fantoni

Presidente da Comissão de Bioética FMVZ/USP 


\section{FOLHA DE AVALIAÇÃO}

Nome: IKUTA, Cássia Yumi

Título: Comparação entre meios de cultura e condições de incubação para o primo isolamento de Mycobacterium bovis de bovinos brasileiros.

Dissertação apresentada ao Programa de PósGraduação em Epidemiologia Experimental e Aplicada às Zoonoses da Faculdade de Medicina Veterinária e Zootecnia da Universidade de São Paulo para obtenção do título de Mestre em Ciências

Data:

\section{BANCA EXAMINADORA}

Prof. Dr.

Instituição

Assinatura

Julgamento

Prof. Dr.

Instituição

Assinatura

Julgamento

Prof. Dr.

Instituição

Assinatura

Julgamento 
Dedico aos meus pais, Clara e Vicente meu irmão, Guto e ao Marcelo, companheiro de todos os momentos...

Por todo apoio e paciência. 


\section{AGRADECIMENTOS}

Ao meu orientador, Prof. Dr. José Soares Ferreira Neto, pela liberdade para aprender e pelo apoio para realizar.

Ao Prof. Dr. Silvio Arruda Vasconcellos, pelo apoio e incentivo a ir além.

Ao Prof. Dr. Marcos Amaku, pela ajuda e compreensão nos assuntos estatísticos.

À Prof $f^{a}$. Dra. Andrea Micke Moreno, Prof. Dr. José Antonio Jerez e Prof. Dr. Fumio Honma Ito, por abrirem as portas de seus laboratórios.

Aos Professores do VPS, por minha formação acadêmica e por sempre terem sido solícitos.

À Flavia e Gisele, pelos momentos dentro e fora do fluxo, à Amane, pelas lembranças de Porto de Galinhas, e às três, pelas conversas e momentos Outback com muitas risadas.

Às colegas do LZB, Érika, Léia, Vanessa, Vivianne e Zenaide, pelos momentos de descontração.

Aos funcionários do VPS, Alexandre, Bispo, Carol, Cristina, Danival, Hilda, Jucélia, Paula, Pedrinho, Priscilla, Renato, Rosana, Sandra, Sheila, Tânia, Virginia e Washington, e pelo companheirismo e ajuda nos momentos de crise.

Aos funcionários da biblioteca, em especial Elza, Helena, Fernanda e Solange, sem as quais não haveria base para escrever esta dissertação.

Aos funcionários do VRA, Belau, Irailton e Luiz, pela ajuda na colheita de sangue.

À Tânia e Will, pelas horas de conversas carregadas de café. 
“- Tenho sede dessa água - disse o principezinho. (...) E eu compreendi o que ele havia buscado! (...) Aquela água era muito mais que um alimento. Nascera da caminhada sob as estrelas, do canto da roldana, do esforço do meu braço." Antoine de Saint-Exupéry (O Pequeno Príncipe) 


\section{RESUMO}

IKUTA, C. Y. Comparação entre meios de cultura e condições de incubação para o primo isolamento de Mycobacterium bovis de bovinos brasileiros. [Comparison between media and incubation conditions for primary isolation of Mycobacterium bovis from Brazilian cattle]. 2011. 77 f. Dissertação. (Mestrado em Ciências) - Faculdade de Medicina Veterinária e Zootecnia, Universidade de São Paulo, São Paulo, 2011.

Considerando que os meios de cultura e as condições de incubação são os principais fatores para o sucesso do primo isolamento, além do método de descontaminação, quatro meios de cultura e três condições de incubação foram investigados. Noventa e sete amostras de lesões granulomatosas foram submetidas ao método de descontaminação com cloreto de 1hexadecilpiridinio (HPC) a 1,5\%, e semeadas em dois meios a base de ovo, Stonebrink e Löwenstein-Jensen com piruvato de sódio, e em dois meios a base de ágar, B83 e Middlebrook 7H11. Cada meio foi incubado a $37^{\circ} \mathrm{C}$ por 90 dias em três condições de incubação, atmosfera com $10 \%$ de $\mathrm{CO}_{2}$, atmosfera normal e atmosfera com suposta tensão de $\mathrm{CO}_{2}$ obtida pela queima do algodão hidrófobo e fechamento do tubo com rolha de cortiça. $\mathrm{O}$ tipo de condição de incubação utilizado teve influência nos meios a base de ovo apenas no inicio da incubação (30 dias), mas nenhuma nos meios a base de ágar. A incubação em atmosfera com $10 \%$ de $\mathrm{CO}_{2}$ diminuiu o tempo de aparecimento da primeira colônia e aumentou o número de UFC. O meio B83 foi mais rápido no aparecimento das colônias e teve o maior sucesso de isolamento aos 30 dias, mas não houve diferença com os meios Stonebrink e Löwenstein-Jensen com piruvato, no sucesso de isolamento e número de UFC aos 60 e 90 dias. De acordo com os dados, em sete oportunidades houve isolamento de M. bovis apenas no meio de Stonebrink e em quatro apenas no B83, assim, sugere-se a utilização desses dois meios de cultura em paralelo, incubados em atmosfera com acréscimo de $\mathrm{CO}_{2}$.

Palavras-chave: Primo isolamento.Tuberculose bovina. Mycobacterium bovis. Meios de cultura. Condições de incubação. 


\begin{abstract}
IKUTA, C. Y. Comparison between media and incubation conditions for primary isolation of Mycobacterium bovis from Brazilian cattle. [Comparação entre meios de cultura e condições de incubação para o primo isolamento de Mycobacterium bovis de bovinos brasileiros]. 2011. 77 f. Dissertação. (Mestrado em Ciências) - Faculdade de Medicina Veterinária e Zootecnia, Universidade de São Paulo, São Paulo, 2011.
\end{abstract}

Considering that the culture media and the incubation conditions are the main factors for the success of primary isolation, besides the decontamination procedure, four culture media and three incubation conditions were investigated. Ninety-seven samples of granulommatous lesions were submitted to the decontamination procedure by 1-hexadecylpyridinium chloride at $1,5 \% \mathrm{w} / \mathrm{v}$, and inoculated on two egg-based media, Stonebrink and Löwenstein-Jensen with sodium pyruvate, and two agar-based media, B83 and Middlebrook 7H11. Each medium was incubated at $37^{\circ} \mathrm{C}$ for 90 days in three incubation conditions, in air containing $10 \% \mathrm{CO}_{2}$, in air, and in air with a supposed higher $\mathrm{CO}_{2}$ tension created by burning the hydrophobic cotton used to close the tubes and subsequently closing with a cork. The type of incubation condition used had influence on the egg-based media only at the beginning of incubation (30 days), but none on the agar-based media. The incubation in air containing $10 \% \mathrm{CO}_{2}$ decreased the time to first appearance of colonies and increased the number of colonies. B83 medium showed a faster growth and detected more isolates at 30 days of incubation. However, there was no difference between B83, Stonebrink and Löwenstein-Jensen with pyruvate at 60 and 90 days of incubation. According to the data, seven M. bovis isolates grew only on Stonebrink and four only on $\mathrm{B} 83$, therefore, the use of both media, in parallel, incubated in air containing $\mathrm{CO}_{2}$ is suggested.

Keywords: Primary isolation. Bovine tuberculosis. Mycobacterium bovis. Culture media. Incubation conditions. 


\section{LISTA DE FOTOS}

Foto 1 - Tubos $18 \times 180 \mathrm{~mm}$ com meio B83 após a incubação com crescimento de colônias escurecidas e translúcidas - São Paulo - 2010 .

Foto 2 - Tubo com meio a base de ovo após a incubação com crescimento de colônias de morfologia e características compatíveis a M. bovis São Paulo - 2010 


\section{LISTA DE TABELAS}

Tabela 1 - Proporção de sucesso de isolamento de M. bovis aos 30 dias de incubação, segundo os meios de cultura - São Paulo - 2010.

Tabela 2 - Valores de "p" resultantes das comparações entre as proporções de sucesso no isolamento de $M$. bovis aos 30 dias de incubação, segundo os meios de cultura - São Paulo - 2010

Tabela 3 - Proporção de sucesso de isolamento de M. bovis aos 60 dias de incubação, segundo os meios de cultura - São Paulo - 2010.

Tabela 4 - Valores de "p" resultantes das comparações entre as proporções de sucesso no isolamento de $M$. bovis aos 60 dias de incubação, segundo os meios de cultura - São Paulo - 2010

Tabela 5 - Proporção de sucesso de isolamento de M. bovis aos 90 dias de incubação, segundo os meios de cultura - São Paulo - 2010.

Tabela 6 - Valores de "p" resultantes das comparações entre as proporções de sucesso no isolamento de $M$. bovis aos 90 dias de incubação, segundo os meios de cultura - São Paulo - 2010

Tabela 7 - Soma de ranks da variável tempo para aparecimento da primeira UFC (dias), segundo os meios de cultura - São Paulo - 2010.

Tabela 8- Valores de "p" resultantes da comparação do tempo para aparecimento da primeira UFC (dias), segundo os meios de cultura São Paulo - 2010

Tabela 9- Soma de ranks do número de UFC aos 30 dias de incubação, segundo os meios de cultura - São Paulo - 2010 
Tabela 10 - Valores de "p" resultantes da comparação do número de UFC aos 30 dias de incubação, segundo os meios de cultura - São Paulo - 2010

Tabela 11 - Soma de ranks do número de UFC aos 60 dias de incubação, segundo os meios de cultura - São Paulo - 2010

Tabela 12 - Valores de "p" resultantes da comparação do número de UFC aos 60 dias de incubação, segundo os meios de cultura - São Paulo - 2010

Tabela 13 - Soma de ranks do número de UFC aos 90 dias de incubação, segundo os meios de cultura - São Paulo - 2010

Tabela 14 - Valores de "p" resultantes da comparação do número de UFC aos 90 dias de incubação, segundo os meios de cultura - São Paulo - 2010 34

Tabela 15 - Proporção de sucesso de isolamento de M. bovis aos 30 dias de incubação, segundo as condições de incubação - São Paulo - 2010

Tabela 16 - Valores de "p" resultantes das comparações das proporções de sucesso no isolamento de $M$. bovis aos 30 dias de incubação, segundo as condições de incubação - São Paulo - 2010 35

Tabela 17 - Proporção de sucesso de isolamento de M. bovis aos 60 dias de incubação, segundo as condições de incubação - São Paulo - 2010

Tabela 18 - Valores de "p" resultantes das comparações das proporções de sucesso no isolamento de $M$. bovis aos 60 dias de incubação, segundo as condições de incubação - São Paulo - 2010 35

Tabela 19 - Proporção de sucesso de isolamento de M. bovis aos 90 dias de incubação, segundo as condições de incubação - São Paulo - 2010 36 
Tabela 20 - Valores de "p" resultantes das comparações das proporções de sucesso no isolamento de $M$. bovis aos 90 dias de incubação, segundo as condições de incubação - São Paulo - 2010

Tabela 21 - Soma de ranks da variável tempo para aparecimento da primeira UFC (dias), segundo as condições de incubação - São Paulo - 2010.

Tabela 22 - Valores de "p" resultantes da comparação do tempo para aparecimento da primeira UFC (dias), segundo as condições de incubação - São Paulo - 2010

Tabela 23 - Soma de ranks do número de UFC aos 30 dias de incubação, segundo as condições de incubação - São Paulo - 2010 38

Tabela 24 - Valores de "p" resultantes da comparação do número de UFC aos 30 dias de incubação, segundo as condições de incubação - São Paulo 2010

Tabela 25 - Soma de ranks do número de UFC aos 60 dias de incubação, segundo as condições de incubação - São Paulo - 2010 39

Tabela 26 - Valores de "p" resultantes da comparação do número de UFC aos 60 dias de incubação, segundo as condições de incubação - São Paulo 2010

Tabela 27 - Soma de ranks do número de UFC aos 90 dias de incubação, segundo as condições de incubação - São Paulo - 2010

Tabela 28 - Valores de "p" resultantes da comparação do número de UFC aos 90 dias de incubação, segundo as condições de incubação - São Paulo 2010 
Tabela 29 - Proporção de sucesso de isolamento de M. bovis aos 30 dias de incubação, segundo os meios de cultura e as condições de incubação - São Paulo - 2010

Tabela 30 - Valores de "p" resultantes das comparações entre as proporções de sucesso no isolamento de $M$. bovis aos 30 dias de incubação, segundo os meios de cultura e as condições de incubação - São Paulo - 2010

Tabela 31 - Proporção de sucesso de isolamento de M. bovis aos 60 dias de incubação, segundo os meios de cultura e as condições de incubação - São Paulo - 2010

Tabela 32 - Valores de "p" resultantes das comparações entre as proporções de sucesso no isolamento de $M$. bovis aos 60 dias de incubação, segundo os meios de cultura e as condições de incubação - São Paulo - 2010

Tabela 33 - Proporção de sucesso de isolamento de M. bovis aos 90 dias de incubação, segundo os meios de cultura e as condições de incubação - São Paulo - 2010 45

Tabela 34 - Valores de "p" resultantes das comparações entre as proporções de sucesso no isolamento de $M$. bovis aos 90 dias de incubação, segundo os meios de cultura e as condições de incubação - São Paulo - 2010 46

Tabela 35 - Soma de ranks da variável tempo para aparecimento da primeira UFC (dias), segundo os meios de cultura e as condições de incubação - São Paulo - 2010

Tabela 36 - Valores de "p" resultantes da comparação do tempo para aparecimento da primeira UFC (dias), segundo os meios de cultura e as condições de incubação - São Paulo - 2010 
Tabela 37 - Soma de ranks do número de UFC aos 30 dias de incubação, segundo os meios de cultura e as condições de incubação - São Paulo - 2010

Tabela 38 - Valores de "p" resultantes da comparação do número de UFC aos 30 dias de incubação, segundo os meios de cultura e as condições de incubação - São Paulo - 2010

Tabela 39 - Soma de ranks do número de UFC aos 60 dias de incubação, segundo os meios de cultura e as condições de incubação - São Paulo - 2010

Tabela 40 - Valores de "p" resultantes da comparação do número de UFC aos 60 dias de incubação, segundo os meios de cultura e as condições de incubação - São Paulo - 2010

Tabela 41 - Soma de ranks do número de UFC aos 90 dias de incubação, segundo os meios de cultura e as condições de incubação - São Paulo - 2010

Tabela 42 - Valores de "p" resultantes da comparação do número de UFC aos 90 dias de incubação, segundo os meios de cultura e as condições de incubação - São Paulo - 2010 


\section{LISTA DE GRÁFICOS}

Gráfico 1 - Proporção de sucesso de isolamento de M. bovis aos 30, 60 e 90 dias, segundo os meios de cultura - São Paulo - 2010.

Gráfico 2 - Proporção de sucesso de isolamento de M. bovis aos 30, 60 e 90 dias, segundo as condições de incubação - São Paulo - 2010 


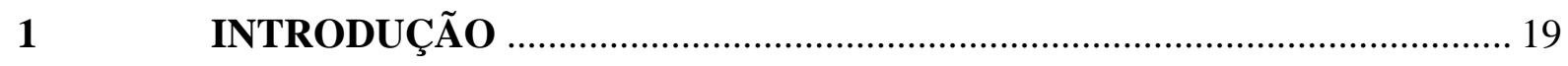

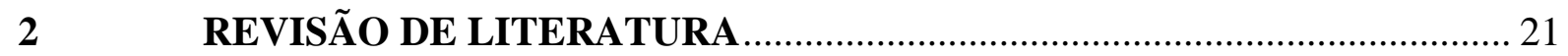

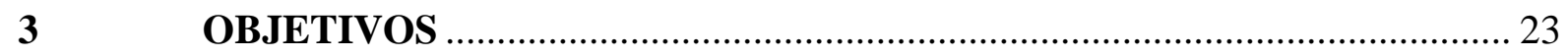

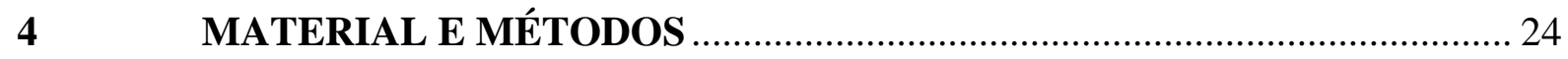

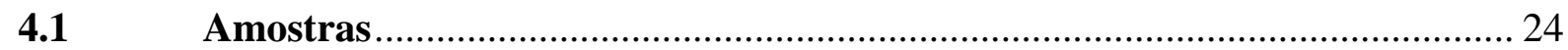

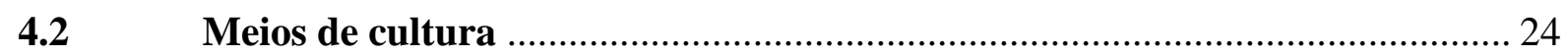

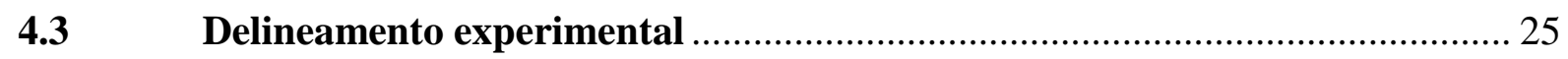

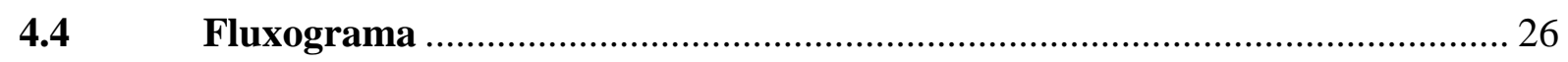

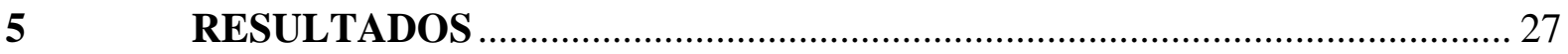

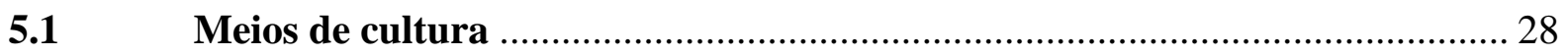

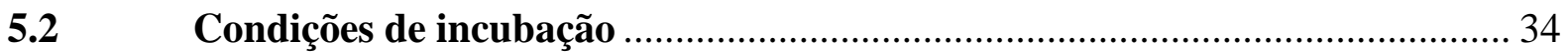

5.3 Meios de cultura e condições de incubação ……………………………........ 40

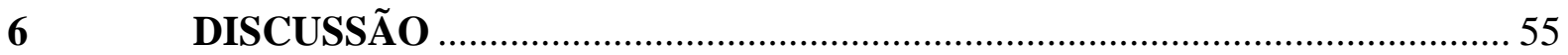

$7 \quad$ CONCLUSÃO

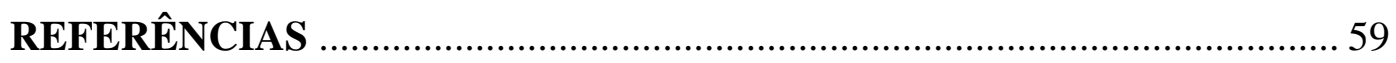

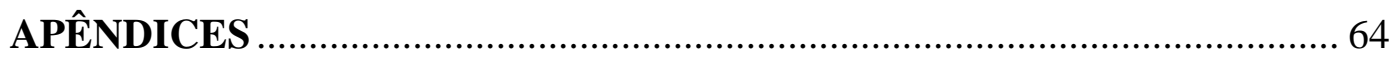

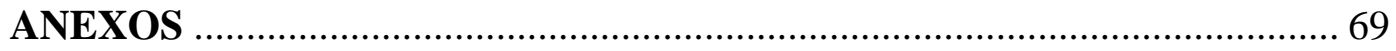




\section{INTRODUÇÃO}

A tuberculose bovina é uma zoonose bem conhecida que ocorre no mundo inteiro (O’REILLY; DABORN, 1995; MODA et al., 1996). Seu agente causador, Mycobacterium bovis, possui uma das variedades mais amplas de hospedeiros entre os patógenos conhecidos e, portanto, mecanismos de transmissão complexos, com interação infecciosa entre seres humanos, animais domésticos e silvestres (MORRIS; PFEIFFER; JACKSON, 1994).

Os casos humanos dessa tuberculose zoonótica têm maior incidência em áreas rurais, geralmente associados à exposição ocupacional, por inalação de aerossóis e contato com carcaças, e sua ocorrência apresenta uma considerável variação regional, dependendo da quantidade de rebanhos infectados, da situação socioeconômica, da aplicação de medidas preventivas (MODA et al., 1996; COSIVI et al., 1998) e dos hábitos alimentares relacionados aos produtos lácteos, principalmente (SMITH, 1898).

Apesar de intensos esforços durante várias décadas, a tuberculose bovina continua a ser um problema significante na perspectiva global, com influência adversa na economia agropecuária em todas as regiões em que está presente (POLLOCK et al., 2006).

Para combater esta doença, os países implementam programas de controle e erradicação, baseados na certificação de propriedades livres e na detecção e saneamento de focos. Essa última atividade é essência de um sistema de vigilância, cuja base é a detecção de lesões tuberculosas em abatedouros, com subseqüente colheita para que o diagnóstico definitivo seja realizado mediante isolamento e identificação. Assim, a propriedade foco pode ser rastreada e saneada (COUSINS, 2001; LAGE et al., 2006; AMBROSIO et al., 2008).

No Brasil, o combate à tuberculose de forma organizada foi iniciado apenas em 2001, com o lançamento do Programa de Controle e Erradicação da Brucelose e Tuberculose (PNCEBT) (LAGE et al., 2006). Entretanto, em virtude das características das cadeias produtivas de carne e leite brasileiras, a expectativa de prevalência da tuberculose bovina é baixa, sobretudo nos estados grandes produtores de carne. Neste ambiente de baixa prevalência, torna-se muito interessante a implementação de sistemas de vigilância visando a detecção e o saneamento dos focos residuais. Assim, como a detecção de focos é feita por métodos diretos de diagnóstico, ou seja, isolamento e identificação do agente a partir de lesões colhidas em abatedouro, a sensibilidade do primo isolamento de $M$. bovis é componente importante da sensibilidade de todo o sistema de vigilância. 
Apesar de muitos estudos com ênfase em diagnóstico in vitro terem sido realizados (SCHAEFER, 1952; GALLAGHER; HORWILL, 1977; CORNER; NICOLACOPOULOS, 1988; CORNER; TRAJSTMAN, 1988; COUSINS; FRANCIS; GOW, 1989; AMBROSIO et al., 2008), é necessário investigar o comportamento de cepas de $M$. bovis circulantes no Brasil em relação aos métodos de primo isolamento, notadamente os meios de cultura e as condições de incubação. 


\section{REVISÃO DE LITERATURA}

Para a obtenção de culturas puras do bacilo da tuberculose bovina, vários estudos foram conduzidos em busca de meios de cultura com o melhor desempenho (SCHAEFER, 1952; BIRN, 1965; GALLAGHER; HORWILL, 1977; CORNER; NICOLACOPOULOS, 1988; COUSINS; FRANCIS; GOW, 1989).

Atualmente, não há muito padrão entre os laboratórios para a escolha dos meios de cultura (CORNER; NICOLACOPOULOS, 1988), mas para assegurar a melhor sensibilidade possível, recomenda-se o uso concomitante dos meios a base de ágar e a base de ovo, já que ambos têm vantagens sobre o outro e nenhum é capaz de detectar $M$. bovis de todas as lesões (TARSHIS, 1953; BIRN, 1965; COUSINS; FRANCIS; GOW, 1989; CORNER, 1994).

As cepas "de campo" requerem meios enriquecidos para seu crescimento (CORNER, 1994), e a adição de piruvato de sódio no meio de cultura tem efeito favorável (SCHAEFER, 1952) por causa da falta de piruvato quinase funcional, que torna o bacilo bovino inapto a usar o glicerol ou qualquer carboidrato para gerar energia (KEATING et al., 2005). Contudo, esse efeito não foi observado no meio Middlebrook 7H11 acrescido de piruvato a $0,4 \%$, por Gallagher e Horwill (1977). Apesar do glicerol em sua composição, o Middlebrook 7H11 promove um crescimento rápido (CORNER; NICOLACOPOULOS, 1988; COUSINS; FRANCIS; GOW, 1989).

Wherry e Ervin ${ }^{1}$ (1918 apud ROCKWELL; HIGHBERGER, 1926, p. 92) foram os primeiros a inferir a necessidade de dióxido de carbono $\left(\mathrm{CO}_{2}\right)$ no cultivo do bacilo da tuberculose.

A partir deste momento, vários estudos foram conduzidos a fim de sanar essa questão. Entretanto, eram dedicados ao isolamento de M. tuberculosis, utilizando meio líquido e cepa de laboratório, H.37 (DAVIES, 1940), e amostras clínicas de esputo semeadas em meio sólido de ágar ou a base de ovo, como Löwenstein-Jensen (SCHAEFER; COHN; MIDDLEBROOK, 1955; WHITCOMB; FOSTER; DUKES, 1962; BEAM; KUBICA, 1968; KRASNOW; WAYNE, 1969; GRUFT; LODER, 1971; CHAUHAN; SREENIVAS; CHAUDHURI, 1991). Em todos os trabalhos, foi observado o aparecimento mais rápido com maior proporção de

\footnotetext{
1 WHERRY, W. B.; ERVIN, D. M. The necessity of carbon dioxide for the growth of B. tuberculosis. The Journal of Infectious Diseases, Chicago, v. 22, p. 194-197, 1918.
} 
isolados, número e tamanho de colônias, quando incubados em atmosfera com aumento da concentração de $\mathrm{CO}_{2}$, desde $2,5 \%$ a $11 \%$.

Diferenças entre $M$. tuberculosis e $M$. bovis, com base nas características de crescimento e reações bioquímicas, já eram evidentes aos pesquisadores antes mesmo do segundo ser nomeado espécie (KARLSON; LESSEL, 1970). Entre elas está a preferência por oxigênio, observada através da inoculação em meio de ágar com consistência semi-sólida, no qual as micobactérias aeróbias crescem apenas próximo da superfície e as microaerófilas têm crescimento profundo, geralmente formando uma banda densa submersa (LEBEK ${ }^{2}, 1959$ apud COLLINS; GRANGE, 1983, p. 17; MARKS, 1972; MARKS, 1976; COLLINS; YATES; GRANGE, 1982; GRANGE; YATES, 1994).

Esta técnica se tornou um teste de identificação (MARKS, 1972; MARKS, 1976; COLLINS; YATES; GRANGE, 1982; GRANGE et al., 1990), pois a taxa de crescimento em meio de ovos não era considerada adequada para determinar a preferência de oxigênio (MARKS, 1976). Entretanto, a presença de debris dos tecidos no meio líquido ou semi-sólido pode causar viés, já que o crescimento é observado pela turvação, e as características de crescimento e a morfologia das colônias, observadas apenas em meio sólido, são fatores usados para a tipificação do organismo (LESSLIE, 1959).

Apesar das várias investigações realizadas, o papel do dióxido de carbono $\left(\mathrm{CO}_{2}\right)$ no primo isolamento de $M$. bovis ainda é controverso (CORNER; NICOLACOPOULOS, 1988; CORNER; TRAJSTMAN, 1988; COUSINS; FRANCIS; GOW, 1989; CORNER, 1994). Inclusive, o "Manual de Testes Diagnósticos e Vacinas para Animais Terrestres 2010" da Organização Mundial de Saúde Animal (OIE) considera a utilização de atmosfera de $\mathrm{CO}_{2}$ uma condição facultativa.

Além dos meios de cultura e das condições de incubação, os métodos de descontaminação podem influenciar o sucesso do primo isolamento de M. bovis. Existem vários protocolos para essa finalidade e os mais utilizados são aqueles que se valem do tratamento da amostra com detergentes, ácidos ou álcalis, sendo que todos têm alguma toxicidade para micobactérias (CORNER; TRAJSTMAN, 1988; CORNER, 1994).

\footnotetext{
${ }^{2}$ LEBEK, G. Dependence of the oxygen optimal concentration of both strains of mammalian mycobacterium tuberculosis on the nutritive substrate. Zentralblatt für Bakteriologie: international journal of medical microbiology, Stuttgart, v. 176, p. 530-537, 1959.
} 


\section{OBJETIVOS}

Visando aperfeiçoar o primo isolamento de Mycobacterium bovis a partir de lesões colhidas de bovinos em abatedouros no Brasil, os objetivos deste experimento foram investigar o comportamento de quatro meios de cultura e três diferentes formas de incubação. 


\section{MATERIAL E MÉTODOS}

\subsection{Amostras}

As amostras utilizadas foram obtidas a partir do projeto "Abatedouros como instrumento de rastreabilidade de focos de tuberculose bovina no Estado de São Paulo. Mapeamento e Epidemiologia Molecular" (Processo FAPESP: 99/12732-7), a partir do qual foi constituída uma coleção de homogeneizados de lesões granulomatosas de bovinos condenados por tuberculose em abatedouros, mantida em laboratório a $-20^{\circ} \mathrm{C}$.

Dessa coleção foram selecionadas 97 amostras, sendo que de 48 delas foi isolado o $M$. bovis no referido projeto e das outras 49 não se logrou êxito na tentativa de isolamento.

\subsection{Meios de Cultura}

Os meios de cultura testados foram: Stonebrink (Anexo A), Löwenstein-Jensen com adição de Piruvato de Sódio (Anexo B), Ágar Sangue Tuberculose, também denominado de B83 (Anexo C), e Middlebrook 7H11 (Anexo D).

Após o preparo de cada meio, 7 a $8 \mathrm{~mL}$ destes foram distribuídos em tubos de vidro 18x180 mm com e sem tampa de rosca. Os meios a base de ovo - Stonebrink e LöwensteinJensen com piruvato - foram levados à coaguladora a $86^{\circ} \mathrm{C}$ durante 40 minutos, e os meios a base de ágar, deixados sobre a bancada até solidificarem-se. Todos foram armazenados em temperatura de refrigeração até o momento do uso. 


\subsection{Delineamento Experimental}

As amostras de homogeneizados escolhidas foram submetidas ao processo de descontaminação com Cloreto de 1-Hexadecilpiridinio (HPC). Este método consiste na adição de HPC a 1,5\% à amostra, em proporção de $1: 1$, seguida de repouso em estufa a $37^{\circ} \mathrm{C}$ por 20 minutos (AMBROSIO et al., 2005) e centrifugação a 3000 r.p.m. durante 20 minutos (CORNER; TRAJSTMAN, 1988).

O sobrenadante de cada amostra foi desprezado e seu sedimento ressuspenso com 3 $\mathrm{mL}$ de solução salina a $0,85 \%$ estéril para semear $100 \mu \mathrm{L}$ em cada tubo, sendo dois com tampa de rosca de baquelite e outro fechado com algodão hidrófobo. Todos semeados em duplicata para cada um dos quatro meios de cultura.

Um dos tubos com tampa de rosca foi incubado em estufa com acréscimo de $10 \%$ de $\mathrm{CO}_{2}$, enquanto o outro foi incubado em estufa normal junto com o tubo fechado com algodão. Para a secagem da superfície, os tubos com tampa de rosca foram mantidos com a tampa semi-aberta a $37^{\circ} \mathrm{C}$ durante 24 horas (CORNER; NICOLACOPOULOS, 1988), permitindo maior tempo de contato do meio com a atmosfera oferecida pela estufa antes do fechamento total. O tubo sem rosca, após esse período sob as mesmas condições, foi submetido à queima do algodão e ao fechamento com rolha de cortiça. A incubação foi feita a $37^{\circ} \mathrm{C}$ durante 90 dias.

As colônias com morfologia e características compatíveis com micobactérias foram coradas pelo método de Ziehl-Neelsen e identificadas pelas técnicas moleculares PRA (Anexo F) e Spoligotyping (Anexo G).

Foram realizadas leituras a cada três dias de incubação e as Unidades Formadoras de Colônias (UFC) de micobactérias foram contadas aos 30, 60 e 90 dias de incubação. Para as análises, foram calculadas as médias dos tubos semeados em duplicata. Quando as UFC eram incontáveis foi adotado o valor de 300 UFC (adaptado de BRASIL, 1993).

As variáveis analisadas foram o tempo em dias para o aparecimento da primeira colônia, o sucesso no isolamento e o número de UFC aos 30, 60 e 90 dias de incubação. A variável sucesso no isolamento foi analisada pelo teste de comparação de proporções com auxílio do programa MedCalc. As variáveis tempo em dias para aparecimento da primeira colônia e número de UFC foram analisadas pelos testes de Friedman e Dunn, com auxílio do programa MiniTab. 


\subsection{Fluxograma}

Segue um esquema para melhor entendimento do procedimento:

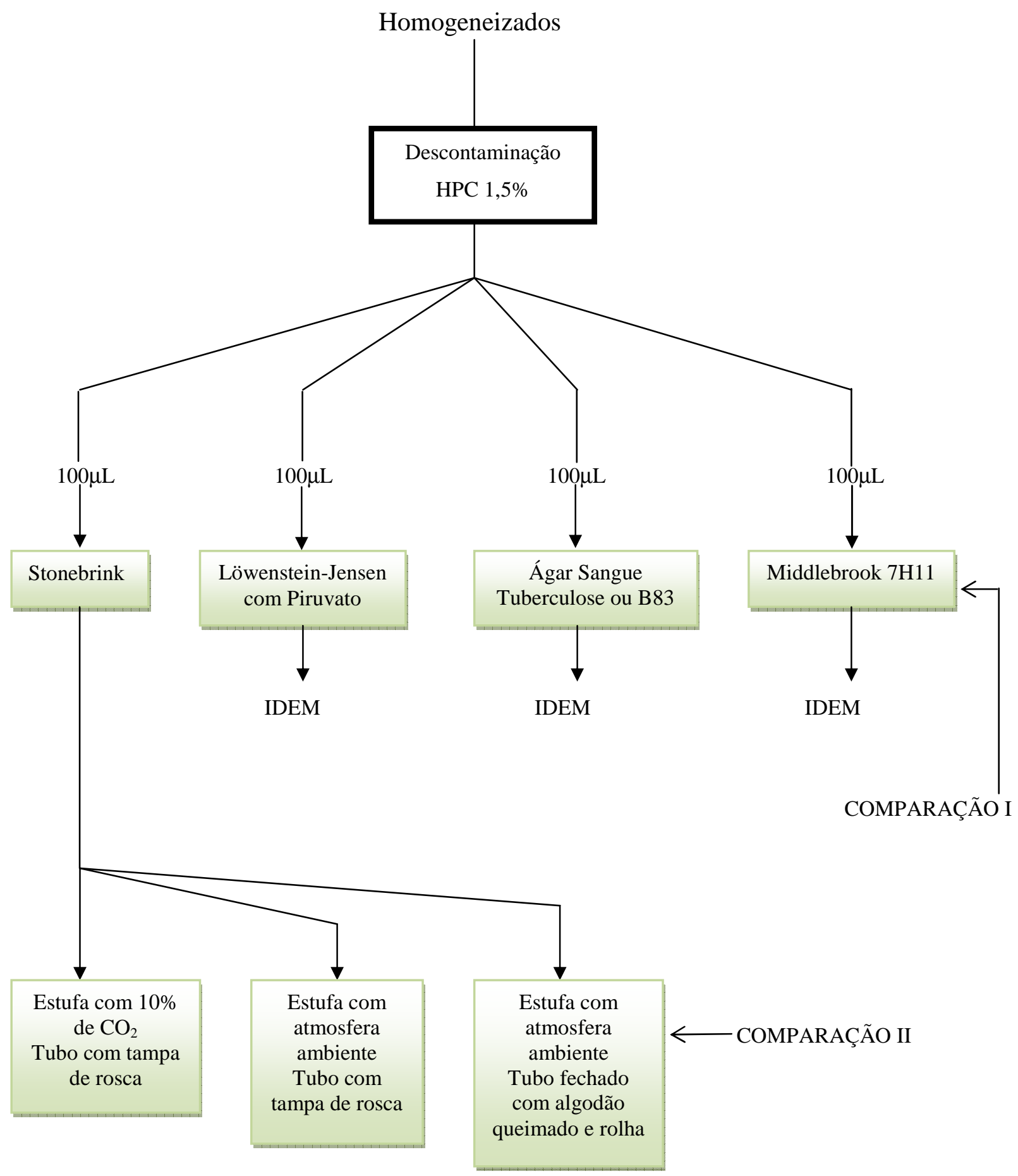




\section{RESULTADOS}

Colônias de Mycobacterium bovis foram isoladas a partir de 46 amostras $(47,4 \%)$ entre as 97 utilizadas no presente estudo (Apêndice A).

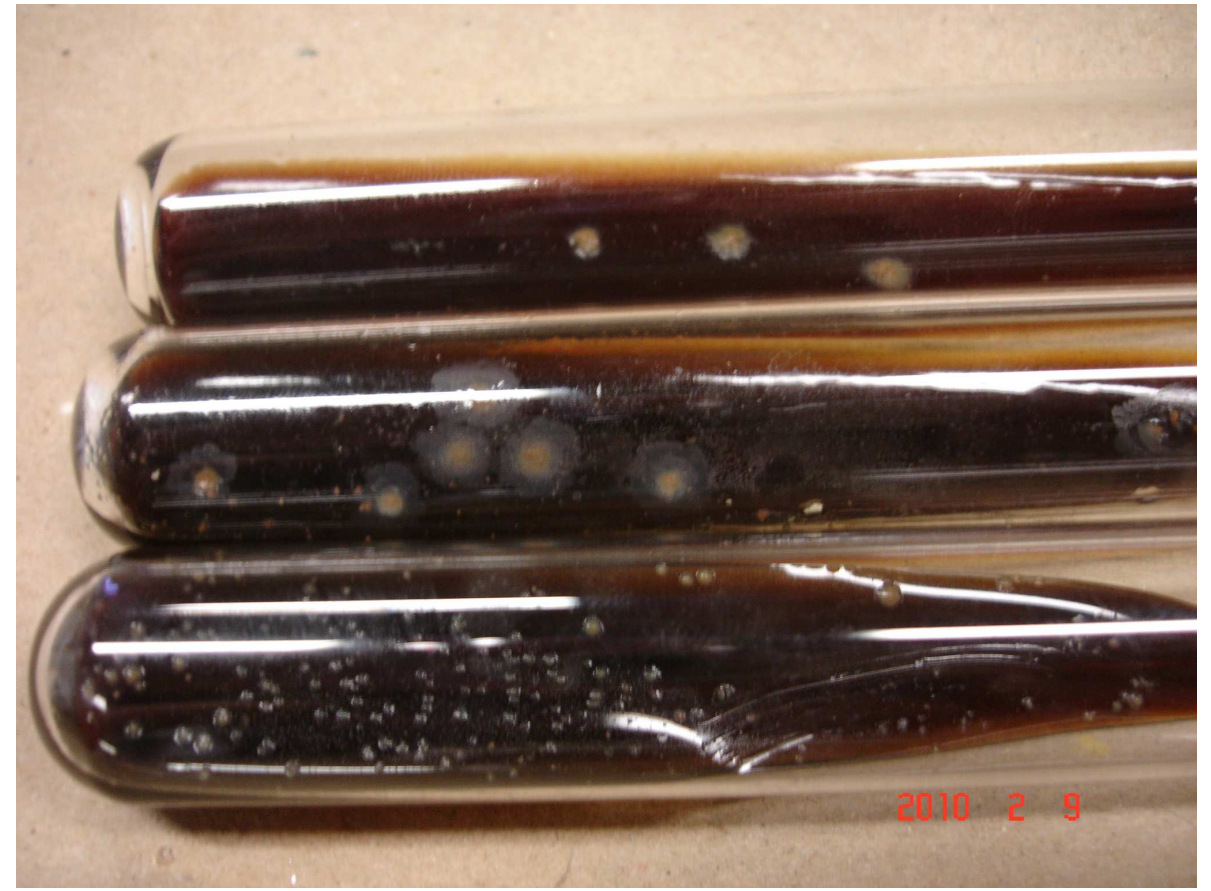

Fonte: Cássia Yumi Ikuta - São Paulo - 2010.

Foto 1 - Tubos 18x180mm com meio B83 após a incubação com crescimento de colônias escurecidas e translúcidas - São Paulo - 2010 


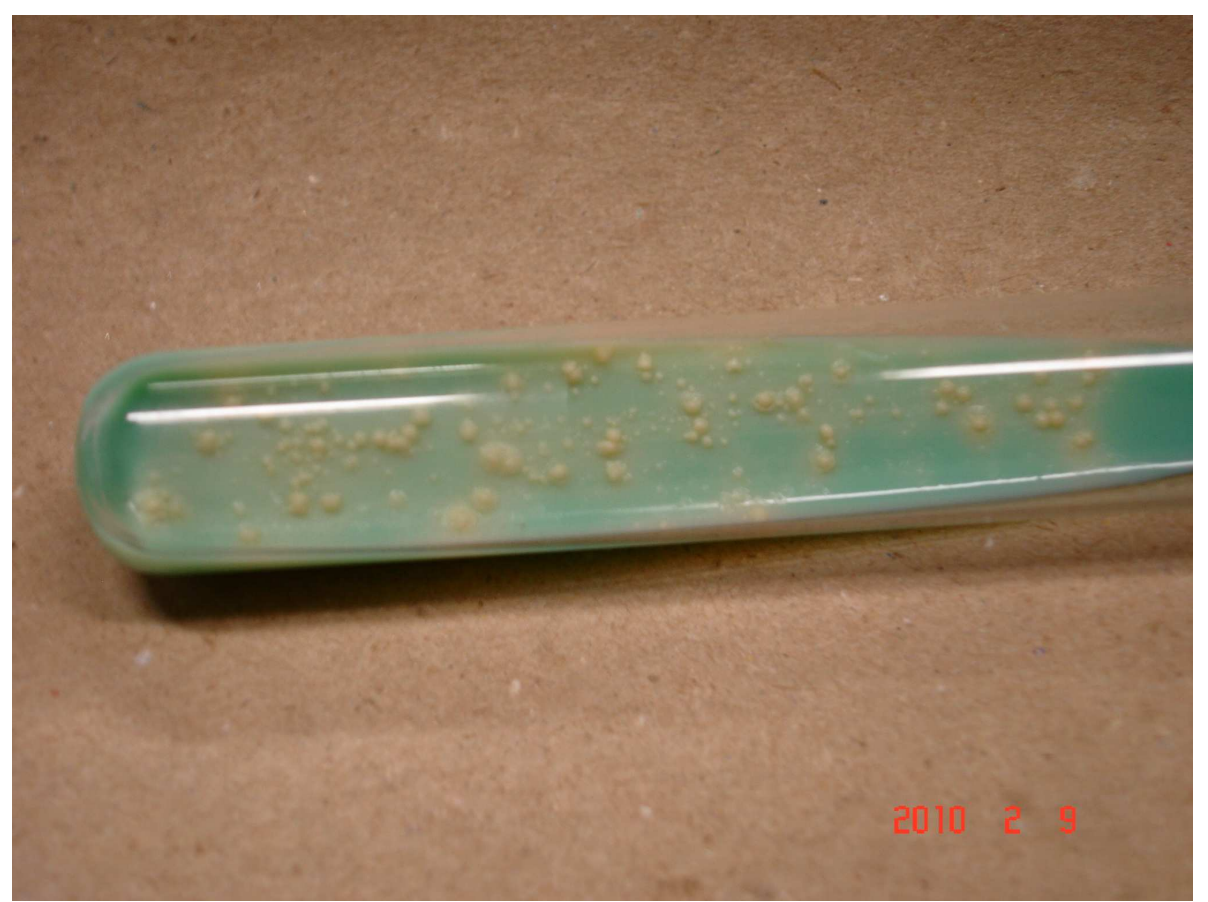

Fonte: Cássia Yumi Ikuta - São Paulo - 2010.

Foto 2 - Tubo 18x180mm com meio a base de ovo após a incubação com crescimento de colônias de morfologia e características compatíveis a M. bovis - São Paulo - 2010

\subsection{Meios de cultura}

As proporções de sucesso de isolamento consolidadas para os meios de cultura e a comparação entre elas nos três momentos de contagem, 30, 60 e 90 dias, são apresentadas nas tabelas 1 a 6 . A progressão do número de isolados pode ser observada no gráfico 1.

Tabela 1 - Proporção de sucesso de isolamento de M. bovis aos 30 dias de incubação, segundo os meios de cultura - São Paulo - 2010

\begin{tabular}{l|cccc}
\hline \multicolumn{5}{c}{30 dias } \\
\hline meios de cultura & Sto $^{1}$ & LJp $^{2}$ & $7 \mathrm{H} 11^{3}$ & B83 $^{4}$ \\
\hline isolados & 41 & 21 & 11 & 64 \\
total & 291 & 291 & 291 & 291 \\
$\%$ & 14,09 & 7,22 & 3,78 & 21,99 \\
\hline${ }^{1}$ Stonebrink; ${ }^{2}$ Löwenstein-Jensen com piruvato; ${ }^{3}$ Middlebrook 7 H11; ${ }^{4}$ Ágar
\end{tabular}


Tabela 2 - Valores de "p" resultantes das comparações entre as proporções de sucesso no isolamento de M. bovis aos 30 dias de incubação, segundo os meios de cultura - São Paulo - 2010

\begin{tabular}{c|ccc}
\hline \multicolumn{4}{|c}{30 dias } \\
\hline variáveis & Sto $^{1}$ & LJp $^{2}$ & $7{\mathrm{H} 11^{3}}^{\circ}$ \\
\hline LJp & 0,0107 & & \\
$7 \mathrm{H} 11$ & $<0,0001$ & 0,1014 & \\
B83 & 0,0178 & $<0,0001$ & $<0,0001$ \\
\hline
\end{tabular}

${ }^{1}$ Stonebrink; ${ }^{2}$ Löwenstein-Jensen com piruvato;

${ }^{3}$ Middlebrook 7H11; ${ }^{4}$ Ágar sangue tuberculose

Tabela 3 - Proporção de sucesso de isolamento de M. bovis aos 60 dias de incubação, segundo os meios de cultura - São Paulo - 2010

\begin{tabular}{l|cccc}
\hline \multicolumn{5}{c}{60 dias } \\
\hline meios de cultura & Sto $^{1}$ & LJp $^{2}$ & $7 \mathrm{H} 11^{3}$ & B83 $^{4}$ \\
\hline isolados & 70 & 68 & 19 & 77 \\
total & 291 & 291 & 291 & 291 \\
$\%$ & 24,05 & 23,37 & 6,53 & 26,46 \\
\hline${ }^{1}$ Stonebrink; ${ }^{2}$ Löwenstein-Jensen com piruvato; ${ }^{3}$ Middlebrook $7 \mathrm{H} 11 ;{ }^{4}$ Ágar \\
sangue tuberculose
\end{tabular}

Tabela 4 - Valores de "p" resultantes das comparações entre as proporções de sucesso no isolamento de M. bovis aos 60 dias de incubação, segundo os meios de cultura - São Paulo - 2010

\begin{tabular}{|c|c|c|c|}
\hline \multicolumn{4}{|c|}{60 dias } \\
\hline variáveis & Sto $^{1}$ & $\mathrm{LJp}^{2}$ & $7 \mathrm{H} 11^{3}$ \\
\hline LJp & 0,924 & & \\
\hline 7H11 & $<0,0001$ & $<0,0001$ & \\
\hline$B 83^{4}$ & 0,5662 & 0,4437 & $<0,0001$ \\
\hline
\end{tabular}

${ }^{1}$ Stonebrink; ${ }^{2}$ Löwenstein-Jensen com piruvato;

${ }^{3}$ Middlebrook 7H11; ${ }^{4}$ Ágar sangue tuberculose 
Tabela 5 - Proporção de sucesso de isolamento de M. bovis aos 90 dias de incubação, segundo os meios de cultura - São Paulo - 2010

\begin{tabular}{l|cccc}
\hline \multicolumn{5}{|c}{90 dias } \\
\hline meios de cultura & Sto $^{1}$ & $\mathrm{LJp}^{2}$ & $7 \mathrm{H} 11^{3}$ & B83 $^{4}$ \\
\hline isolados & 76 & 73 & 21 & 78 \\
total & 291 & 291 & 291 & 291 \\
$\%$ & 26,12 & 25,09 & 7,22 & 26,80 \\
\hline
\end{tabular}

${ }^{1}$ Stonebrink; ${ }^{2}$ Löwenstein-Jensen com piruvato; ${ }^{3}$ Middlebrook 7 H11; ${ }^{4}$ Ágar sangue tuberculose

Tabela 6 - Valores de "p" resultantes das comparações entre as proporções de sucesso no isolamento de M. bovis aos 90 dias de incubação, segundo os meios de cultura - São Paulo - 2010

\begin{tabular}{c|ccc}
\hline \multicolumn{4}{|c}{90 dias } \\
\hline variáveis & Sto $^{1}$ & LJp $^{2}$ & $7 \mathrm{H} 11^{3}$ \\
\hline LJp & 0,8496 & & \\
$7 \mathrm{H} 11$ & $<0,0001$ & $<0,0001$ & \\
B83 $^{4}$ & 0,9267 & 0,7069 & $<0,0001$ \\
\hline
\end{tabular}

${ }^{1}$ Stonebrink; ${ }^{2}$ Löwenstein-Jensen com piruvato;

${ }^{3}$ Middlebrook 7H11; ${ }^{4}$ Ágar sangue tuberculose 


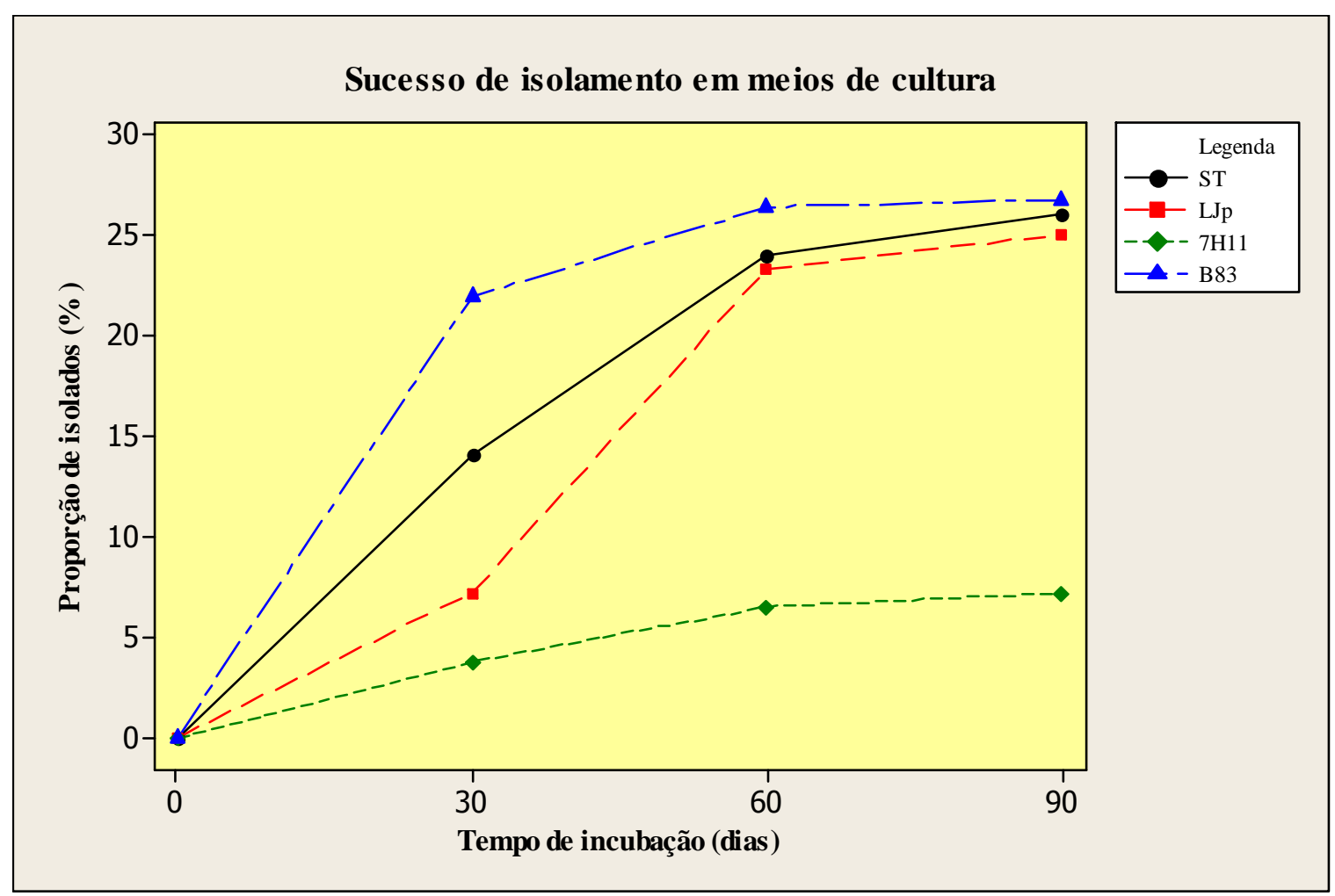

Gráfico 1 - Proporção de sucesso de isolamento de M. bovis aos 30, 60 e 90 dias, segundo os meios de cultura São Paulo - 2010

As somas de ranks, consolidadas para os meios de cultura, da variável tempo para aparecimento da primeira UFC (dias) e a comparação entre elas são apresentadas nas tabelas 7 e 8 .

Tabela 7 - Soma de ranks da variável tempo para aparecimento da primeira UFC (dias), segundo os meios de cultura - São Paulo - 2010

\begin{tabular}{c|c}
\hline meios de cultura & Soma dos ranks \\
\hline B83 $^{1}$ & 282,5 \\
Sto $^{2}$ & 306 \\
LJp $^{3}$ & 357 \\
$7 \mathrm{H} 11^{4}$ & 434,5 \\
\hline
\end{tabular}

${ }^{1}$ Ágar sangue tuberculose; ${ }^{2}$ Stonebrink; ${ }^{3}$ Löwenstein-

Jensen com piruvato; ${ }^{4}$ Middlebrook $7 \mathrm{H} 11$ 
Tabela 8 - Valores de "p" resultantes da comparação do tempo para aparecimento da primeira UFC (dias), segundo os meios de cultura - São Paulo - 2010

\begin{tabular}{c|ccc}
\hline variáveis & Sto $^{1}$ & $\mathrm{LJp}^{2}$ & $7 \mathrm{H} 11^{3}$ \\
\hline $\mathrm{LJp}$ & $>0,05$ & & \\
$7 \mathrm{H} 11$ & $<0,001$ & $<0,01$ & \\
$\mathrm{~B} 83{ }^{4}$ & $>0,05$ & $<0,01$ & $<0,001$ \\
\hline \multicolumn{1}{l}{ Stonebrink; ${ }^{2}$ Löwenstein-Jensen com piruvato; } \\
\multicolumn{3}{l}{ Middlebrook $7 \mathrm{H} 11 ;{ }^{4}$ Ágar sangue tuberculose }
\end{tabular}

As somas de ranks dos números de UFC consolidadas para os meios de cultura e a comparação entre elas aos 30, 60 e 90 dias são apresentadas nas tabelas 9 a 14.

Tabela 9 - Soma de ranks do número de UFC aos 30 dias de incubação, segundo os meios de cultura - São Paulo $-2010$

\begin{tabular}{c|c}
\hline 30dias & Soma dos ranks \\
\hline B83 $^{1}$ & 404 \\
Sto $^{2}$ & 361 \\
LJp $^{3}$ & 317 \\
$7 \mathrm{H} 11^{4}$ & 298 \\
\hline
\end{tabular}

${ }^{1}$ Ágar sangue tuberculose;
${ }^{2}$ Stonebrink; ${ }^{3}$ Löwenstein-Jensen com
piruvato; ${ }^{4}$ Middlebrook $7 \mathrm{H} 11$.

Tabela 10 - Valores de "p" resultantes da comparação do número de UFC aos 30 dias de incubação, segundo os meios de cultura - São Paulo - 2010

\begin{tabular}{c|ccc}
\hline \multicolumn{4}{|c}{30 dias } \\
\hline variáveis & \multicolumn{4}{|c}{ Sto $^{1}$} & LJp $^{2}$ & $7 \mathrm{H} 11^{3}$ \\
\hline LJp & $>0,05$ & & \\
$7 \mathrm{H} 11$ & $<0,05$ & $>0,05$ & \\
$\mathrm{~B}^{4} 3^{4}$ & $>0,05$ & $<0,001$ & $<0,001$ \\
\hline
\end{tabular}

${ }^{1}$ Stonebrink; ${ }^{2}$ Löwenstein-Jensen com piruvato;

${ }^{3}$ Middlebrook 7H11; ${ }^{4}$ Ágar sangue tuberculose 
Tabela 11 - Soma de ranks do número de UFC aos 60 dias de incubação, segundo os meios de cultura - São Paulo - 2010

\begin{tabular}{c|c}
\hline 60dias & Soma dos ranks \\
\hline B $83^{1}$ & 379 \\
Sto $^{2}$ & 372 \\
LJp $^{3}$ & 372 \\
$7 \mathrm{H} 11^{4}$ & 257 \\
\hline${ }^{1}$ Ágar sangue tuberculose; \\
${ }^{2}$ Stonebrink; ${ }^{3}$ Löwenstein-Jensen com \\
piruvato; ${ }^{4}$ Middlebrook 7H11.
\end{tabular}

Tabela 12 - Valores de "p" resultantes da comparação do número de UFC aos 60 dias de incubação, segundo os meios de cultura - São Paulo - 2010

\begin{tabular}{c|ccc}
\hline \multicolumn{4}{|c}{60 dias } \\
\hline variáveis & Sto $^{1}$ & LJp $^{2}$ & $7 \mathrm{H} 11^{3}$ \\
\hline LJp & $>0,05$ & & \\
$7 \mathrm{H} 11$ & $<0,001$ & $<0,001$ & \\
$\mathrm{~B}^{4} 3^{4}$ & $>0,05$ & $>0,05$ & $<0,001$ \\
\hline
\end{tabular}

${ }^{1}$ Stonebrink; ${ }^{2}$ Löwenstein-Jensen com piruvato;

${ }^{3}$ Middlebrook 7H11; ${ }^{4}$ Ágar sangue tuberculose

Tabela 13 - Soma de ranks do número de UFC aos 90 dias de incubação, segundo os meios de cultura - São Paulo - 2010

\begin{tabular}{c|c}
\hline 90dias & Soma dos ranks \\
\hline LJp $^{1}$ & 377 \\
Sto $^{2}$ & 375,5 \\
B83 & 373 \\
$7 \mathrm{H} 11^{4}$ & 254,5 \\
\hline
\end{tabular}

${ }^{1}$ Löwenstein-Jensen com piruvato;

${ }^{2}$ Stonebrink; ${ }^{3}$ Ágar sangue

tuberculose; ${ }^{4}$ Middlebrook 7H11 
Tabela 14 - Valores de "p" resultantes da comparação do número de UFC aos 90 dias de incubação, segundo os meios de cultura - São Paulo - 2010

\begin{tabular}{c|ccc}
\hline \multicolumn{4}{c}{90 dias } \\
\hline variáveis & Sto $^{1}$ & LJp $^{2}$ & $7 \mathrm{H} 11^{3}$ \\
\hline LJp & $>0,05$ & & \\
$7 \mathrm{H} 11$ & $<0,001$ & $<0,001$ & \\
B83 & $>0,05$ & $>0,05$ & $<0,001$ \\
\hline${ }^{1}$ Stonebrink; ${ }^{2}$ Löwenstein-Jensen com piruvato; \\
${ }^{3}$ Middlebrook 7H11; ${ }^{4}$ Ágar sangue tuberculose
\end{tabular}

\subsection{Condições de incubação}

As proporções de sucesso de isolamento consolidadas para as condições de incubação e a comparação entre elas nos três momentos de contagem, 30, 60 e 90 dias, são apresentadas nas tabelas 15 a 20. A progressão do número de isolados pode ser observada no gráfico 2.

Tabela 15 - Proporção de sucesso de isolamento de M. bovis aos 30 dias de incubação, segundo as condições de incubação- São Paulo - 2010

\begin{tabular}{l|ccc}
\hline \multicolumn{4}{c}{30 dias } \\
\hline condição de incubação & $\mathrm{CO}_{2}{ }^{1}$ & $\mathrm{NOR}^{2}$ & $\mathrm{QUE}^{3}$ \\
\hline isolados & 76 & 33 & 28 \\
total & 388 & 388 & 388 \\
$\%$ & 19,59 & 8,51 & 7,22 \\
\hline
\end{tabular}

${ }^{1}$ Atmosfera com $10 \%$ de $\mathrm{CO} 2 ;{ }^{2}$ Atmosfera ambiente; ${ }^{3}$ Algodão queimado. 
Tabela 16 - Valores de "p" resultantes das comparações das proporções de sucesso no isolamento de M. bovis aos 30 dias de incubação, segundo as condições de incubação - São Paulo - 2010

\begin{tabular}{c|cc}
\hline \multicolumn{3}{|c}{30 dias } \\
\hline variáveis & $\mathrm{CO}_{2}{ }^{1}$ & $\mathrm{NOR}^{2}$ \\
\hline NOR & $<0,0001$ \\
$\mathrm{QUE}^{3}$ & $<0,0001$ & 0,5933 \\
\hline${ }^{1}$ Atmosfera com 10\% de $\mathrm{CO} 2 ;$ \\
${ }^{2}$ Atmosfera ambiente; ${ }^{3}$ Algodão \\
queimado.
\end{tabular}

Tabela 17 - Proporção de sucesso de isolamento de M. bovis aos 60 dias de incubação, segundo as condições de incubação - São Paulo - 2010

\begin{tabular}{l|ccc}
\hline \multicolumn{4}{c}{60 dias } \\
\hline condição de incubação & $\mathrm{CO}_{2}{ }^{1}$ & $\mathrm{NOR}^{2}$ & $\mathrm{QUE}^{3}$ \\
\hline isolados & 90 & 76 & 68 \\
total & 388 & 388 & 388 \\
$\%$ & 23,20 & 19,59 & 17,53 \\
\hline${ }^{1}$ Atmosfera com 10\% de CO2 $;{ }^{2}$ Atmosfera ambiente; ${ }^{3}$ Algodão \\
queimado.
\end{tabular}

Tabela 18 - Valores de "p" resultantes das comparações das proporções de sucesso no isolamento de M. bovis aos 60 dias de incubação, segundo as condições de incubação - São Paulo - 2010

\begin{tabular}{c|cc}
\hline \multicolumn{3}{|c}{60 dias } \\
\hline variáveis & $\mathrm{CO}_{2}{ }^{1}$ & $\mathrm{NOR}^{2}$ \\
\hline NOR & 0,2549 & \\
$\mathrm{QUE}^{3}$ & 0,0612 & 0,5185 \\
\hline
\end{tabular}

${ }^{1}$ Atmosfera com $10 \%$ de $\mathrm{CO} 2$;

${ }^{2}$ Atmosfera ambiente; ${ }^{3}$ Algodão queimado. 
Tabela 19 - Proporção de sucesso de isolamento de M. bovis aos 90 dias de incubação, segundo as condições de incubação - São Paulo - 2010

\begin{tabular}{l|ccc}
\hline \multicolumn{4}{c}{90 dias } \\
\hline condição de incubação & $\mathrm{CO}_{2}{ }^{1}$ & $\mathrm{NOR}^{2}$ & $\mathrm{QUE}^{3}$ \\
\hline isolados & 94 & 81 & 73 \\
total & 388 & 388 & 388 \\
$\%$ & 24,23 & 20,88 & 18,81 \\
\hline
\end{tabular}

${ }^{1}$ Atmosfera com $10 \%$ de $\mathrm{CO} 2 ;{ }^{2}$ Atmosfera ambiente; ${ }^{3}$ Algodão queimado.

Tabela 20 - Valores de "p" resultantes das comparações das proporções de sucesso no isolamento de M. bovis aos 90 dias de incubação, segundo as condições de incubação - São Paulo - 2010

\begin{tabular}{c|cc}
\hline \multicolumn{3}{|c}{90 dias } \\
\hline variáveis & $\mathrm{CO}_{2}{ }^{1}$ & $\mathrm{NOR}^{2}$ \\
\hline NOR & 0,3028 & \\
QUE $^{3}$ & 0,0802 & 0,5268 \\
\hline
\end{tabular}

${ }^{1}$ Atmosfera com $10 \%$ de $\mathrm{CO} 2$;

${ }^{2}$ Atmosfera ambiente; ${ }^{3}$ Algodão

queimado. 


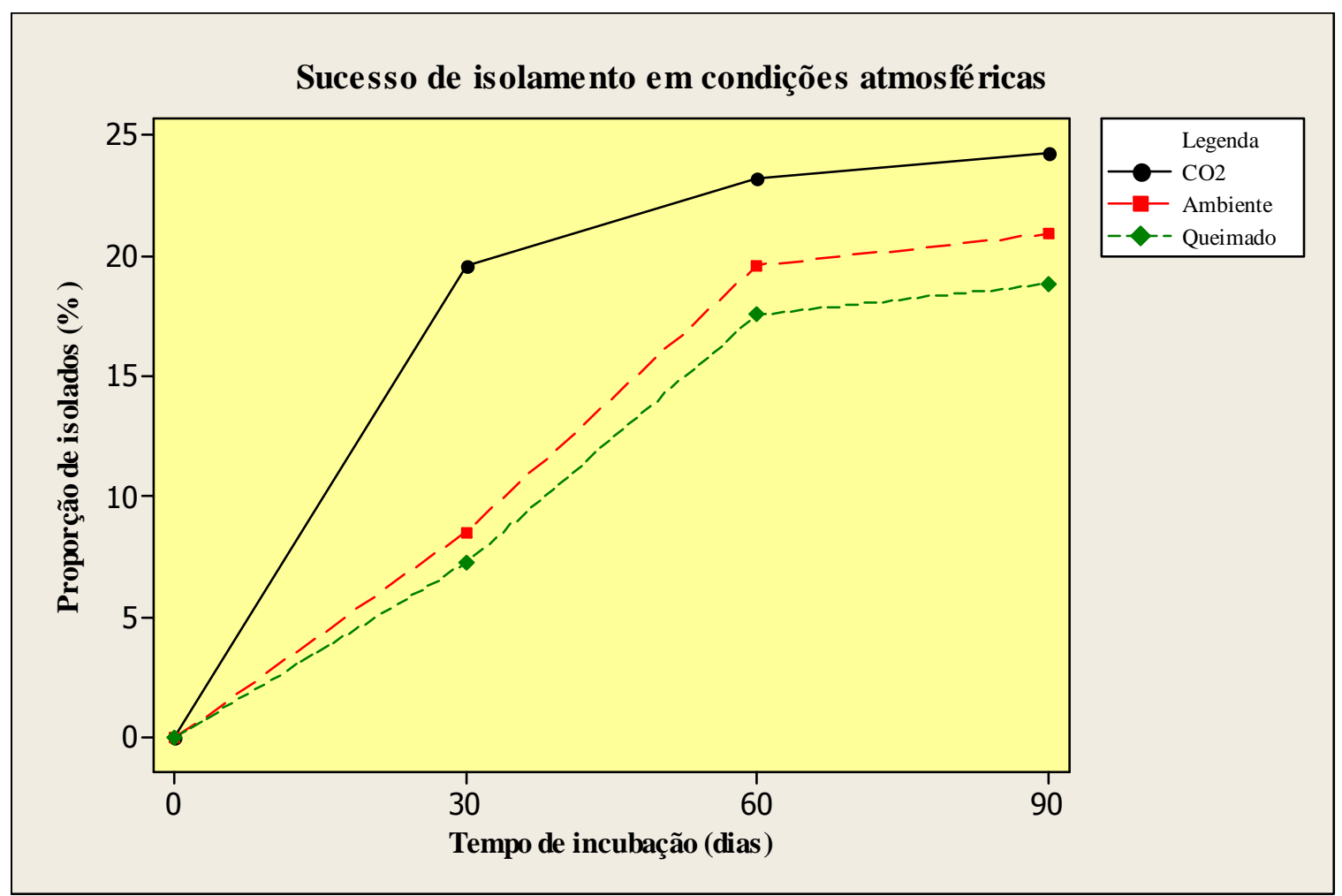

Gráfico 2 - Proporção de sucesso de isolamento de M. bovis aos 30, 60 e 90 dias, segundo as condições de incubação - São Paulo - 2010

As somas de ranks, consolidadas para as condições de incubação, da variável tempo para aparecimento da primeira UFC (dias) e a comparação entre elas são apresentadas nas tabelas 21 e 22 .

Tabela 21 - Soma de ranks da variável tempo para aparecimento da primeira UFC (dias), segundo as condições de incubação - São Paulo - 2010

\begin{tabular}{c|c}
\hline condição de incubação & Soma dos ranks \\
\hline $\mathrm{CO}_{2}{ }^{1}$ & 302,5 \\
$\mathrm{NOR}^{2}$ & 397,5 \\
$\mathrm{QUE}^{3}$ & 404 \\
\hline
\end{tabular}

${ }^{1}$ Atmosfera com $10 \%$ de CO2 ; ${ }^{2}$ Atmosfera ambiente;

${ }^{3}$ Algodão queimado. 
Tabela 22 - Valores de "p" resultantes da comparação do tempo para aparecimento da primeira UFC (dias), segundo as condições de incubação - São Paulo - 2010

\begin{tabular}{c|cc}
\hline variáveis & $\mathrm{CO}_{2}{ }^{1}$ & $\mathrm{NOR}^{2}$ \\
\hline NOR & $<0,001$ & \\
QUE $^{3}$ & $<0,001$ & $>0,05$ \\
\hline
\end{tabular}

${ }^{1}$ Atmosfera com $10 \%$ de $\mathrm{CO} 2$;

${ }^{2}$ Atmosfera ambiente; ${ }^{3}$ Algodão

queimado.

As somas de ranks dos números de UFC consolidadas para as condições de incubação e a comparação entre elas aos 30, 60 e 90 dias são apresentadas nas tabelas 23 a 28.

Tabela 23 - Soma de ranks do número de UFC aos 30 dias de incubação, segundo as condições de incubação São Paulo - 2010

\begin{tabular}{c|c}
\hline 30dias & Soma dos ranks \\
\hline $\mathrm{CO}_{2}{ }^{1}$ & 429,5 \\
$\mathrm{NOR}^{2}$ & 341,5 \\
$\mathrm{QUE}^{3}$ & 333 \\
\hline
\end{tabular}

${ }^{1}$ Atmosfera com $10 \%$ de $\mathrm{CO} 2$;

${ }^{2}$ Atmosfera ambiente; ${ }^{3}$ Algodão queimado.

Tabela 24 - Valores de "p" resultantes da comparação do número de UFC aos 30 dias de incubação, segundo as condições de incubação - São Paulo - 2010

\begin{tabular}{c|cc}
\hline \multicolumn{3}{|c}{30 dias } \\
\hline variáveis & $\mathrm{CO}_{2}{ }^{1}$ & $\mathrm{NOR}^{2}$ \\
\hline NOR & $<0,001$ & \\
$\mathrm{QUE}^{3}$ & $<0,001$ & $>0,05$ \\
\hline
\end{tabular}

${ }^{1}$ Atmosfera com $10 \%$ de $\mathrm{CO} 2$;

${ }^{2}$ Atmosfera ambiente; ${ }^{3}$ Algodão queimado. 
Tabela 25 - Soma de ranks do número de UFC aos 60 dias de incubação, segundo as condições de incubação São Paulo - 2010

\begin{tabular}{c|c}
\hline 60dias & Soma dos ranks \\
\hline $\mathrm{CO}_{2}{ }^{1}$ & 422 \\
$\mathrm{QUE}^{2}$ & 341,5 \\
$\mathrm{NOR}^{3}$ & 340,5 \\
\hline${ }^{1}$ Atmosfera com 10\% de CO2; \\
${ }^{2}$ Algodão queimado; ${ }^{3}$ Atmosfera \\
ambiente.
\end{tabular}

Tabela 26 - Valores de "p" resultantes da comparação do número de UFC aos 60 dias de incubação, segundo as condições de incubação - São Paulo - 2010

\begin{tabular}{c|cc}
\hline \multicolumn{3}{|c}{60 dias } \\
\hline variáveis & $\mathrm{CO}_{2}{ }^{1}$ & $\mathrm{NOR}^{2}$ \\
\hline $\mathrm{NOR}^{2}$ & $<0,001$ & \\
$\mathrm{QUE}^{3}$ & $<0,001$ & $>0,05$ \\
\hline
\end{tabular}

${ }^{1}$ Atmosfera com $10 \%$ de $\mathrm{CO} 2$;

${ }^{2}$ Atmosfera ambiente; ${ }^{3}$ Algodão queimado.

Tabela 27 - Soma de ranks do número de UFC aos 90 dias de incubação, segundo as condições de incubação São Paulo - 2010

\begin{tabular}{c|c}
\hline 90dias & Soma dos ranks \\
\hline $\mathrm{CO}_{2}{ }^{1}$ & 415,5 \\
$\mathrm{NOR}^{2}$ & 348,5 \\
$\mathrm{QUE}^{3}$ & 340 \\
\hline
\end{tabular}

${ }^{1}$ Atmosfera com $10 \%$ de $\mathrm{CO} 2$;

${ }^{2}$ Atmosfera ambiente; ${ }^{3}$ Algodão queimado. 
Tabela 28 - Valores de "p" resultantes da comparação do número de UFC aos 90 dias de incubação, segundo as condições de incubação - São Paulo - 2010

\begin{tabular}{c|cc}
\hline \multicolumn{3}{c}{90 dias } \\
\hline variáveis & $\mathrm{CO}_{2}{ }^{1}$ & $\mathrm{NOR}^{2}$ \\
\hline NOR & $<0,01$ & \\
$\mathrm{QUE}^{3}$ & $<0,001$ & $>0,05$ \\
\hline
\end{tabular}

\subsection{Meios de cultura e condições de incubação}

As proporções de sucesso de isolamento para os meios de cultura e as condições de incubação, e a comparação entre elas nos três momentos de contagem, 30, 60 e 90 dias, são apresentadas nas tabelas 29 a 34. 
Tabela 29 - Proporção de sucesso de isolamento de M. bovis aos 30 dias de incubação, segundo os meios de cultura e as condições de incubação - São Paulo - 2010

\begin{tabular}{|c|c|c|c|c|c|c|c|c|c|c|c|c|}
\hline \multirow{4}{*}{30 dias } & \multicolumn{12}{|c|}{ meios de cultura } \\
\hline & \multicolumn{3}{|c|}{ Sto $^{1}$} & \multicolumn{3}{|c|}{$\mathrm{LJp}^{2}$} & \multicolumn{3}{|c|}{$7 \mathrm{H} 11^{3}$} & \multicolumn{3}{|c|}{$\mathrm{B}_{8} 3^{4}$} \\
\hline & \multicolumn{3}{|c|}{ condição de incubação } & \multicolumn{3}{|c|}{ condição de incubação } & \multicolumn{3}{|c|}{ condição de incubação } & \multicolumn{3}{|c|}{ condição de incubação } \\
\hline & $\mathrm{CO}_{2}^{5}$ & $\mathrm{NOR}^{6}$ & $\mathrm{QUE}^{7}$ & $\mathrm{CO}_{2}$ & NOR & QUE & $\mathrm{CO}_{2}$ & NOR & QUE & $\mathrm{CO}_{2}$ & NOR & QUE \\
\hline isolados & 27 & 10 & 4 & 20 & 1 & 0 & 4 & 3 & 4 & 25 & 19 & 20 \\
\hline total & 97 & 97 & 97 & 97 & 97 & 97 & 97 & 97 & 97 & 97 & 97 & 97 \\
\hline$\%$ & 27,84 & 10,31 & 4,12 & 20,62 & 1,03 & 0,00 & 4,12 & 3,09 & 4,12 & 25,77 & 19,59 & 20,62 \\
\hline
\end{tabular}

${ }^{1}$ Stonebrink; ${ }^{2}$ Löwenstein-Jensen com piruvato; ${ }^{3}$ Middlebrook $7 \mathrm{H} 11 ;{ }^{4}$ Ágar sangue tuberculose; ${ }^{5}$ Atmosfera com $10 \%$ de CO2; ${ }^{6}$ Atmosfera ambiente; ${ }^{7}$ Algodão queimado. 
Tabela 30 - Valores de "p" resultantes das comparações entre as proporções de sucesso no isolamento de M. bovis aos 30 dias de incubação, segundo os meios de cultura e as condições de incubação - São Paulo - 2010

\begin{tabular}{|c|c|c|c|c|c|c|c|c|c|c|c|c|}
\hline \multicolumn{13}{|c|}{30 dias } \\
\hline \multirow{2}{*}{\multicolumn{2}{|c|}{ variáveis }} & \multicolumn{11}{|c|}{ meios de cultura } \\
\hline & & \multicolumn{3}{|c|}{ Sto $^{1}$} & \multicolumn{3}{|c|}{$\mathrm{LJp}^{2}$} & \multicolumn{3}{|c|}{$7 \mathrm{H} 11^{3}$} & \multicolumn{2}{|c|}{$\mathrm{B} 83^{4}$} \\
\hline meios de cultura & condição de incubação & $\mathrm{CO}_{2}^{5}$ & $\mathrm{NOR}^{6}$ & $\mathrm{QUE}^{7}$ & $\mathrm{CO}_{2}$ & NOR & QUE & $\mathrm{CO}_{2}$ & NOR & QUE & $\mathrm{CO}_{2}$ & NOR \\
\hline Sto & NOR & 0,0034 & & & & & & & & & & \\
\hline & QUE & $<0,0001$ & 0,1649 & & & & & & & & & \\
\hline \multirow{3}{*}{ LJp } & $\mathrm{CO}_{2}$ & 0,3144 & 0,0739 & 0,0011 & & & & & & & & \\
\hline & NOR & $<0,0001$ & 0,013 & 0,3653 & $<0,0001$ & & & & & & & \\
\hline & QUE & $<0,0001$ & 0,0035 & 0,1299 & $<0,0001$ & 0,9993 & & & & & & \\
\hline \multirow{3}{*}{ 7H11 } & $\mathrm{CO}_{2}$ & $<0,0001$ & 0,1649 & 0,7179 & 0,0011 & 0,3653 & 0,1299 & & & & & \\
\hline & NOR & $<0,0001$ & 0,0847 & 0,9997 & 0,0004 & 0,6139 & 0,245 & 0,9997 & & & & \\
\hline & QUE & $<0,0001$ & 0,1649 & 0,7179 & 0,0011 & 0,3653 & 0,1299 & 0,7179 & 0,9997 & & & \\
\hline \multirow{3}{*}{ B83 } & $\mathrm{CO}_{2}$ & 0,8702 & 0,009 & 0,0001 & 0,4967 & $<0,0001$ & $<0,0001$ & 0,0001 & $<0,0001$ & 0,0001 & & \\
\hline & NOR & 0,2372 & 0,1072 & 0,0019 & 0,9999 & 0,0001 & $<0,0001$ & 0,0019 & 0,0007 & 0,0019 & 0,3918 & \\
\hline & QUE & 0,3144 & 0,0739 & 0,0011 & 0,8591 & $<0,0001$ & $<0,0001$ & 0,0011 & 0,0004 & 0,0011 & 0,4967 & 0,9999 \\
\hline
\end{tabular}

${ }^{1}$ Stonebrink; ${ }^{2}$ Löwenstein-Jensen com piruvato; ${ }^{3}$ Middlebrook $7 \mathrm{H} 11 ;{ }^{4}$ Ágar sangue tuberculose; ${ }^{5}$ Atmosfera com $10 \%$ de CO2; ${ }^{6}$ Atmosfera ambiente; ${ }^{7}$ Algodão queimado. 
Tabela 31 - Proporção de sucesso de isolamento de M. bovis aos 60 dias de incubação, segundo os meios de cultura e as condições de incubação - São Paulo - 2010

\begin{tabular}{|c|c|c|c|c|c|c|c|c|c|c|c|c|}
\hline \multirow{4}{*}{60 dias } & \multicolumn{12}{|c|}{ meios de cultura } \\
\hline & \multicolumn{3}{|c|}{ Sto $^{1}$} & \multicolumn{3}{|c|}{$\mathrm{LJp}^{2}$} & \multicolumn{3}{|c|}{$7 \mathrm{H} 11^{3}$} & \multicolumn{3}{|c|}{${\mathrm{B} 83^{4}}^{4}$} \\
\hline & \multicolumn{3}{|c|}{ condição de incubação } & \multicolumn{3}{|c|}{ condição de incubação } & \multicolumn{3}{|c|}{ condição de incubação } & \multicolumn{3}{|c|}{ condição de incubação } \\
\hline & $\mathrm{CO}_{2}^{5}$ & $\mathrm{NOR}^{6}$ & $\mathrm{QUE}^{7}$ & $\mathrm{CO}_{2}$ & NOR & QUE & $\mathrm{CO}_{2}$ & NOR & QUE & $\mathrm{CO}_{2}$ & NOR & QUE \\
\hline isolados & 28 & 24 & 18 & 24 & 20 & 24 & 9 & 6 & 4 & 29 & 26 & 22 \\
\hline total & 97 & 97 & 97 & 97 & 97 & 97 & 97 & 97 & 97 & 97 & 97 & 97 \\
\hline$\%$ & 28,87 & 24,74 & 18,56 & 24,74 & 20,62 & 24,74 & 9,28 & 6,19 & 4,12 & 29,90 & 26,80 & 22,68 \\
\hline
\end{tabular}

${ }^{1}$ Stonebrink; ${ }^{2}$ Löwenstein-Jensen com piruvato; ${ }^{3}$ Middlebrook $7 \mathrm{H} 11 ;{ }^{4}$ Ágar sangue tuberculose; ${ }^{5}$ Atmosfera com $10 \%$ de CO2; ${ }^{6}$ Atmosfera ambiente; ${ }^{7}$ Algodão queimado. 
Tabela 32 - Valores de "p" resultantes das comparações entre as proporções de sucesso no isolamento de $M$. bovis aos 60 dias de incubação, segundo os meios de cultura e as condições de incubação - São Paulo - 2010

\begin{tabular}{|c|c|c|c|c|c|c|c|c|c|c|c|c|}
\hline \multicolumn{13}{|c|}{60 dias } \\
\hline \multirow{2}{*}{\multicolumn{2}{|c|}{ variáveis }} & \multicolumn{11}{|c|}{ meios de cultura } \\
\hline & & \multicolumn{3}{|c|}{$\mathrm{Sto}^{1}$} & \multicolumn{3}{|c|}{$\mathrm{LJp}^{2}$} & \multicolumn{3}{|c|}{$7 \mathrm{H} 11^{3}$} & \multicolumn{2}{|c|}{$\mathrm{B} 83^{4}$} \\
\hline meios de cultura & condição de incubação & $\mathrm{CO}_{2}{ }^{5}$ & $\mathrm{NOR}^{6}$ & $\mathrm{QUE}^{7}$ & $\mathrm{CO}_{2}$ & NOR & QUE & $\mathrm{CO}_{2}$ & NOR & QUE & $\mathrm{CO}_{2}$ & NOR \\
\hline \multirow{2}{*}{ Sto } & NOR & 0,6261 & & & & & & & & & & \\
\hline & QUE & 0,1287 & 0,3839 & & & & & & & & & \\
\hline \multirow{3}{*}{ LJp } & $\mathrm{CO}_{2}$ & 0,6261 & 0,8679 & 0,3839 & & & & & & & & \\
\hline & NOR & 0,244 & 0,6074 & 0,8567 & 0,6074 & & & & & & & \\
\hline & QUE & 0,6261 & 0,8679 & 0,3839 & 0,8679 & 0,6074 & & & & & & \\
\hline \multirow{3}{*}{$7 \mathrm{H} 11$} & $\mathrm{CO}_{2}$ & 0,001 & 0,0075 & 0,097 & 0,0075 & 0,0441 & 0,0075 & & & & & \\
\hline & NOR & 0,0001 & 0,0007 & 0,0165 & 0,0007 & 0,0062 & 0,0007 & 0,5914 & & & & \\
\hline & QUE & $<0,0001$ & 0,0001 & 0,0032 & 0,0001 & 0,0011 & 0,0001 & 0,2501 & 0,7435 & & & \\
\hline \multirow{3}{*}{ B83 } & $\mathrm{CO}_{2}$ & 0,9999 & 0,5187 & 0,0938 & 0,5187 & 0,1861 & 0,5187 & 0,0006 & $<0,0001$ & $<0,0001$ & & \\
\hline & NOR & 0,8717 & 0,8698 & 0,2306 & 0,8698 & 0,3991 & 0,8698 & 0,0028 & 0,0002 & $<0,0001$ & 0,7492 & \\
\hline & QUE & 0,4114 & 0,8662 & 0,5949 & 0,8662 & 0,8619 & 0,8662 & 0,0187 & 0,0022 & 0,0003 & 0,3275 & 0,6181 \\
\hline
\end{tabular}

${ }^{1}$ Stonebrink; ${ }^{2}$ Löwenstein-Jensen com piruvato; ${ }^{3}$ Middlebrook $7 \mathrm{H} 11 ;{ }^{4}$ Ágar sangue tuberculose; ${ }^{5}$ Atmosfera com $10 \%$ de CO2; ${ }^{6}$ Atmosfera ambiente; ${ }^{7}$ Algodão queimado. 
Tabela 33 - Proporção de sucesso de isolamento de M. bovis aos 90 dias de incubação, segundo os meios de cultura e as condições de incubação - São Paulo - 2010

\begin{tabular}{|c|c|c|c|c|c|c|c|c|c|c|c|c|}
\hline \multirow{4}{*}{90 dias } & \multicolumn{12}{|c|}{ meios de cultura } \\
\hline & \multicolumn{3}{|c|}{ Sto $^{1}$} & \multicolumn{3}{|c|}{$\mathrm{LJp}^{2}$} & \multicolumn{3}{|c|}{$7 \mathrm{H} 11^{3}$} & \multicolumn{3}{|c|}{$\mathrm{B}_{8} 3^{4}$} \\
\hline & \multicolumn{3}{|c|}{ condição de incubação } & \multicolumn{3}{|c|}{ condição de incubação } & \multicolumn{3}{|c|}{ condição de incubação } & \multicolumn{3}{|c|}{ condição de incubação } \\
\hline & $\mathrm{CO}_{2}{ }^{5}$ & $\mathrm{NOR}^{6}$ & $\mathrm{QUE}^{7}$ & $\mathrm{CO}_{2}$ & NOR & QUE & $\mathrm{CO}_{2}$ & NOR & QUE & $\mathrm{CO}_{2}$ & NOR & QUE \\
\hline isolados & 29 & 26 & 21 & 25 & 22 & 26 & 11 & 6 & 4 & 29 & 27 & 22 \\
\hline total & 97 & 97 & 97 & 97 & 97 & 97 & 97 & 97 & 97 & 97 & 97 & 97 \\
\hline$\%$ & 29,90 & 26,80 & 21,65 & 25,77 & 22,68 & 26,80 & 11,34 & 6,19 & 4,12 & 29,90 & 27,84 & 22,68 \\
\hline
\end{tabular}

${ }^{1}$ Stonebrink; ${ }^{2}$ Löwenstein-Jensen com piruvato; ${ }^{3}$ Middlebrook 7 H1 $1 ;{ }^{4}$ Ágar sangue tuberculose; ${ }^{5}$ Atmosfera com $10 \%$ de CO2; ${ }^{6}$ Atmosfera ambiente; ${ }^{7}$ Algodão queimado. 
Tabela 34 - Valores de "p" resultantes das comparações entre as proporções de sucesso no isolamento de M. bovis aos 90 dias de incubação, segundo os meios de cultura e as condições de incubação - São Paulo - 2010

\begin{tabular}{|c|c|c|c|c|c|c|c|c|c|c|c|c|}
\hline \multicolumn{13}{|c|}{90 dias } \\
\hline \multirow{2}{*}{\multicolumn{2}{|c|}{ variáveis }} & \multicolumn{11}{|c|}{ meios de cultura } \\
\hline & & \multicolumn{3}{|c|}{ Sto $^{1}$} & \multicolumn{3}{|c|}{$\mathrm{LJp}^{2}$} & \multicolumn{3}{|c|}{$7 \mathrm{H} 11^{3}$} & \multicolumn{2}{|c|}{$\mathrm{B} 83^{4}$} \\
\hline meios de cultura & condição de incubação & $\mathrm{CO}_{2}^{5}$ & $\mathrm{NOR}^{6}$ & $\mathrm{QUE}^{7}$ & $\mathrm{CO}_{2}$ & NOR & QUE & $\mathrm{CO}_{2}$ & NOR & QUE & $\mathrm{CO}_{2}$ & NOR \\
\hline \multirow{2}{*}{ Sto } & NOR & 0,7492 & & & & & & & & & & \\
\hline & QUE & 0,2504 & 0,5032 & & & & & & & & & \\
\hline \multirow{3}{*}{ LJp } & $\mathrm{CO}_{2}$ & 0,6301 & 0,9999 & 0,613 & & & & & & & & \\
\hline & NOR & 0,3275 & 0,6181 & 0,9999 & 0,7379 & & & & & & & \\
\hline & QUE & 0,7492 & 0,8712 & 0,5032 & 0,9999 & 0,6181 & & & & & & \\
\hline \multirow{3}{*}{$7 \mathrm{H} 11$} & $\mathrm{CO}_{2}$ & 0,0025 & 0,0105 & 0,0817 & 0,0164 & 0,056 & 0,0105 & & & & & \\
\hline & NOR & $<0,0001$ & 0,0002 & 0,0037 & 0,0004 & 0,0022 & 0,0002 & 0,3104 & & & & \\
\hline & QUE & $<0,0001$ & $<0,0001$ & 0,0006 & 0,0001 & 0,0003 & $<0,0001$ & 0,1065 & 0,7435 & & & \\
\hline \multirow{3}{*}{ B83 } & $\mathrm{CO}_{2}$ & 0,8754 & 0,7492 & 0,2504 & 0,6301 & 0,3275 & 0,7492 & 0,0025 & $<0,0001$ & $<0,0001$ & & \\
\hline & NOR & 0,8743 & 0,9989 & 0,4051 & 0,8702 & 0,5081 & 0,9989 & 0,0066 & 0,0001 & $<0,0001$ & 0,8743 & \\
\hline & QUE & 0,3275 & 0,6181 & 0,9999 & 0,7379 & 0,8639 & 0,6181 & 0,056 & 0,0022 & 0,0003 & 0,3275 & 0,5081 \\
\hline
\end{tabular}

${ }^{1}$ Stonebrink; ${ }^{2}$ Löwenstein-Jensen com piruvato; ${ }^{3}$ Middlebrook $7 \mathrm{H} 11 ;{ }^{4}$ Ágar sangue tuberculose; ${ }^{5}$ Atmosfera com $10 \%$ de CO2; ${ }^{6}$ Atmosfera ambiente; ${ }^{7}$ Algodão queimado. 
As somas de ranks, para os meios de cultura e as condições de incubação, da variável tempo para aparecimento da primeira UFC (dias) e a comparação entre elas são apresentadas nas tabelas 35 e 36 (Apêndice E).

Tabela 35 - Soma de ranks da variável tempo para aparecimento da primeira UFC (dias), segundo os meios de cultura e as condições de incubação - São Paulo - 2010

\begin{tabular}{c|c|c}
\hline meios de cultura & condição de incubação & Soma dos ranks \\
\hline Sto $^{1}$ & $\mathrm{CO}_{2}{ }^{5}$ & 176,5 \\
$\mathrm{~B}^{2} 3^{2}$ & $\mathrm{CO}_{2}$ & 198,5 \\
$\mathrm{LJp}^{3}$ & $\mathrm{CO}_{2}$ & 240,5 \\
$\mathrm{~B} 83$ & $\mathrm{NOR}^{6}$ & 252 \\
$\mathrm{~B} 83$ & $\mathrm{QUE}^{7}$ & 267 \\
Sto & $\mathrm{NOR}$ & 295 \\
LJp & $\mathrm{QUE}$ & 324,5 \\
Sto & $\mathrm{QUE}$ & 330 \\
LJp & $\mathrm{NOR}$ & 343,5 \\
$7 \mathrm{H} 11^{4}$ & $\mathrm{CO}$ & 375 \\
$7 \mathrm{H} 11$ & $\mathrm{NOR}$ & 391,5 \\
7H11 & QUE & 394 \\
\hline
\end{tabular}

${ }^{1}$ Stonebrink; ${ }^{2}$ Ágar sangue tuberculose; ${ }^{3}$ Löwenstein-Jensen com piruvato; ${ }^{4}$ Middlebrook 7H1 1; ${ }^{5}$ Atmosfera com $10 \%$ de CO2; ${ }^{6}$ Atmosfera ambiente;

${ }^{7}$ Algodão queimado. 
Tabela 36 - Valores de "p" resultantes da comparação do tempo para aparecimento da primeira UFC (dias), segundo os meios de cultura e as condições de incubação - São Paulo -2010

\begin{tabular}{|c|c|c|c|c|c|c|c|c|c|c|c|c|}
\hline \multirow{2}{*}{\multicolumn{2}{|c|}{ variáveis }} & \multicolumn{11}{|c|}{ meios de cultura } \\
\hline & & \multicolumn{3}{|c|}{ Sto $^{1}$} & \multicolumn{3}{|c|}{$\mathrm{LJp}^{2}$} & \multicolumn{3}{|c|}{$7 \mathrm{H} 11^{3}$} & \multicolumn{2}{|c|}{$B 83^{4}$} \\
\hline meios de cultura & condição de incubação & $\mathrm{CO}_{2}^{5}$ & $\mathrm{NOR}^{6}$ & $\mathrm{QUE}^{7}$ & $\mathrm{CO}_{2}$ & NOR & QUE & $\mathrm{CO}_{2}$ & NOR & QUE & $\mathrm{CO}_{2}$ & NOR \\
\hline \multirow{2}{*}{ Sto } & NOR & $<0,05$ & & & & & & & & & & \\
\hline & QUE & $<0,001$ & $>0,05$ & & & & & & & & & \\
\hline \multirow{3}{*}{ LJp } & $\mathrm{CO}_{2}$ & $>0,05$ & $>0,05$ & $>0,05$ & & & & & & & & \\
\hline & NOR & $<0,001$ & $>0,05$ & $>0,05$ & $>0,05$ & & & & & & & \\
\hline & QUE & $<0,01$ & $>0,05$ & $>0,05$ & $>0,05$ & $>0,05$ & & & & & & \\
\hline \multirow{3}{*}{ 7H11 } & $\mathrm{CO}_{2}$ & $<0,001$ & $>0,05$ & $>0,05$ & $<0,01$ & $>0,05$ & $>0,05$ & & & & & \\
\hline & NOR & $<0,001$ & $>0,05$ & $>0,05$ & $<0,001$ & $>0,05$ & $>0,05$ & $>0,05$ & & & & \\
\hline & QUE & $<0,001$ & $>0,05$ & $>0,05$ & $<0,001$ & $>0,05$ & $>0,05$ & $>0,05$ & $>0,05$ & & & \\
\hline \multirow{3}{*}{ B83 } & $\mathrm{CO}_{2}$ & $>0,05$ & $>0,05$ & $<0,01$ & $>0,05$ & $<0,01$ & $<0,05$ & $<0,001$ & $<0,001$ & $<0,001$ & & \\
\hline & NOR & $>0,05$ & $>0,05$ & $>0,05$ & $>0,05$ & $>0,05$ & $>0,05$ & $<0,05$ & $<0,01$ & $<0,01$ & $>0,05$ & \\
\hline & QUE & $>0,05$ & $>0,05$ & $>0,05$ & $>0,05$ & $>0,05$ & $>0,05$ & $>0,05$ & $<0,05$ & $<0,05$ & $>0,05$ & $>0,05$ \\
\hline
\end{tabular}

${ }^{1}$ Stonebrink; ${ }^{2}$ Ágar sangue tuberculose; ${ }^{3}$ Löwenstein-Jensen com piruvato; ${ }^{4}$ Middlebrook $7 \mathrm{H} 11 ;{ }^{5}$ Atmosfera com $10 \%$ de CO2; ${ }^{6}$ Atmosfera ambiente ${ }^{; 7}$ Algodão queimado. 
As somas de ranks dos números de UFC para os meios de cultura e as condições de incubação, e a comparação entre elas aos 30, 60 e 90 dias são apresentadas nas tabelas 37 a 42 (Apêndices B a D).

Tabela 37 - Soma de ranks do número de UFC aos 30 dias de incubação, segundo os meios de cultura e as condições de incubação - São Paulo - 2010

\begin{tabular}{c|c|c}
\hline \multicolumn{2}{|c}{ 30dias } \\
\hline meios de cultura & condição de incubação & Soma dos ranks \\
\hline Sto & CO $^{5}$ & 405 \\
B83 $^{2}$ & $\mathrm{CO}_{2}$ & 397 \\
LJp $^{3}$ & $\mathrm{CO}_{2}$ & 358 \\
B83 & $\mathrm{QUE}^{6}$ & 337,5 \\
B83 & $\mathrm{NOR}^{7}$ & 333 \\
Sto & $\mathrm{NOR}^{4}$ & 281,5 \\
$7 \mathrm{H} 11^{4}$ & $\mathrm{NOR}$ & 258 \\
Sto & $\mathrm{QUE}^{2}$ & 254 \\
$7 \mathrm{H} 11$ & $\mathrm{QUE}^{2}$ & 252,5 \\
$7 \mathrm{H} 11$ & $\mathrm{CO}$ & 250,5 \\
LJp & $\mathrm{NOR}$ & 230,5 \\
LJp & QUE & 230,5 \\
\hline
\end{tabular}

${ }^{1}$ Stonebrink; ${ }^{2}$ Ágar sangue tuberculose; ${ }^{3}$ Löwenstein-Jensen com piruvato;

${ }^{4}$ Middlebrook 7H11; ${ }^{5}$ Atmosfera com $10 \%$ de CO2; ${ }^{6}$ Algodão queimado;

${ }^{7}$ Atmosfera ambiente. 
Tabela 38 - Valores de “p” resultantes da comparação do número de UFC aos 30 dias de incubação, segundo os meios de cultura e as condições de incubação - São Paulo 2010

\begin{tabular}{|c|c|c|c|c|c|c|c|c|c|c|c|c|}
\hline \multicolumn{13}{|c|}{30 dias } \\
\hline \multirow{2}{*}{\multicolumn{2}{|c|}{ variáveis }} & \multicolumn{11}{|c|}{ meios de cultura } \\
\hline & & \multicolumn{3}{|c|}{ Sto $^{1}$} & \multicolumn{3}{|c|}{$\mathrm{LJp}^{2}$} & \multicolumn{3}{|c|}{$7 \mathrm{H} 11^{3}$} & \multicolumn{2}{|c|}{${\mathrm{B} 83^{4}}^{4}$} \\
\hline meios de cultura & condição de incubação & $\mathrm{CO}_{2}^{5}$ & $\mathrm{NOR}^{6}$ & $\mathrm{QUE}^{7}$ & $\mathrm{CO}_{2}$ & NOR & QUE & $\mathrm{CO}_{2}$ & NOR & QUE & $\mathrm{CO}_{2}$ & NOR \\
\hline \multirow{2}{*}{ Sto } & NOR & $<0,05$ & & & & & & & & & & \\
\hline & QUE & $<0,001$ & $>0,05$ & & & & & & & & & \\
\hline \multirow{3}{*}{ LJp } & $\mathrm{CO}_{2}$ & $>0,05$ & $>0,05$ & $>0,05$ & & & & & & & & \\
\hline & NOR & $<0,001$ & $>0,05$ & $>0,05$ & $<0,05$ & & & & & & & \\
\hline & QUE & $<0,001$ & $>0,05$ & $>0,05$ & $<0,05$ & $>0,05$ & & & & & & \\
\hline \multirow{3}{*}{$7 \mathrm{H} 11$} & $\mathrm{CO}_{2}$ & $<0,001$ & $>0,05$ & $>0,05$ & $>0,05$ & $>0,05$ & $>0,05$ & & & & & \\
\hline & NOR & $<0,01$ & $>0,05$ & $>0,05$ & $>0,05$ & $>0,05$ & $>0,05$ & $>0,05$ & & & & \\
\hline & QUE & $<0,001$ & $>0,05$ & $>0,05$ & $>0,05$ & $>0,05$ & $>0,05$ & $>0,05$ & $>0,05$ & & & \\
\hline \multirow{3}{*}{ B83 } & $\mathrm{CO}_{2}$ & $>0,05$ & $>0,05$ & $<0,01$ & $>0,05$ & $<0,001$ & $<0,001$ & $<0,01$ & $<0,01$ & $<0,01$ & & \\
\hline & NOR & $>0,05$ & $>0,05$ & $>0,05$ & $>0,05$ & $>0,05$ & $>0,05$ & $<0,05$ & $>0,05$ & $>0,05$ & $>0,05$ & \\
\hline & QUE & $>0,05$ & $>0,05$ & $>0,05$ & $>0,05$ & $>0,05$ & $>0,05$ & $>0,05$ & $>0,05$ & $>0,05$ & $>0,05$ & $>0,05$ \\
\hline
\end{tabular}

${ }^{1}$ Stonebrink; ${ }^{2}$ Löwenstein-Jensen com piruvato; ${ }^{3}$ Middlebrook $7 \mathrm{H} 11 ;{ }^{4}$ Ágar sangue tuberculose; ${ }^{5}$ Atmosfera com $10 \%$ de CO2; ${ }^{6}$ Atmosfera ambiente; ${ }^{7}$ Algodão queimado. 
Tabela 39 - Soma de ranks do número de UFC aos 60 dias de incubação, segundo os meios de cultura e as condições de incubação - São Paulo - 2010

\begin{tabular}{c|c|c}
\hline \multicolumn{3}{|c}{ 60dias } \\
\hline meios de cultura & condição de incubação & Soma dos ranks \\
\hline B83 $^{1}$ & $\mathrm{CO}_{2}{ }^{2}$ & 387,5 \\
Sto $^{2}$ & $\mathrm{CO}_{2}$ & 379 \\
LJp $^{3}$ & $\mathrm{CO}_{2}$ & 362 \\
B83 & NOR $^{6}$ & 316 \\
LJp & QUE $^{7}$ & 315,5 \\
Sto & NOR & 308,5 \\
LJp & NOR & 297 \\
Sto & QUE & 297 \\
B83 & QUE & 295 \\
$7 H 11^{4}$ & CO & 216 \\
$7 H 11$ & NOR & 212 \\
$7 H 11$ & QUE & 202,5 \\
\hline
\end{tabular}

${ }^{1}$ Ágar sangue tuberculose; ${ }^{2}$ Stonebrink; ${ }^{3}$ Löwenstein-Jensen com piruvato; ${ }^{4}$ Middlebrook 7H11; ${ }^{5}$ Atmosfera com $10 \%$ de CO2; ${ }^{6}$ Atmosfera ambiente;

${ }^{7}$ Algodão queimado. 
Tabela 40 - Valores de “p” resultantes da comparação do número de UFC aos 60 dias de incubação, segundo os meios de cultura e as condições de incubação - São Paulo 2010

\begin{tabular}{|c|c|c|c|c|c|c|c|c|c|c|c|c|}
\hline \multicolumn{13}{|c|}{60 dias } \\
\hline \multirow{2}{*}{\multicolumn{2}{|c|}{ variáveis }} & \multicolumn{11}{|c|}{ meios de cultura } \\
\hline & & \multicolumn{3}{|c|}{ Sto $^{1}$} & \multicolumn{3}{|c|}{$\mathrm{LJp}^{2}$} & \multicolumn{3}{|c|}{$7 \mathrm{H} 11^{3}$} & \multicolumn{2}{|c|}{$\mathrm{B} 83^{4}$} \\
\hline meios de cultura & condição de incubação & $\mathrm{CO}_{2}^{5}$ & $\mathrm{NOR}^{6}$ & $\mathrm{QUE}^{7}$ & $\mathrm{CO}_{2}$ & NOR & QUE & $\mathrm{CO}_{2}$ & NOR & QUE & $\mathrm{CO}_{2}$ & NOR \\
\hline \multirow{2}{*}{ Sto } & NOR & $>0,05$ & & & & & & & & & & \\
\hline & QUE & $>0,05$ & $>0,05$ & & & & & & & & & \\
\hline \multirow{3}{*}{ LJp } & $\mathrm{CO}_{2}$ & $>0,05$ & $>0,05$ & $>0,05$ & & & & & & & & \\
\hline & NOR & $>0,05$ & $>0,05$ & $>0,05$ & $>0,05$ & & & & & & & \\
\hline & QUE & $>0,05$ & $>0,05$ & $>0,05$ & $>0,05$ & $>0,05$ & & & & & & \\
\hline \multirow{3}{*}{$7 \mathrm{H} 11$} & $\mathrm{CO}_{2}$ & $<0,001$ & $>0,05$ & $>0,05$ & $<0,01$ & $>0,05$ & $>0,05$ & & & & & \\
\hline & NOR & $<0,001$ & $>0,05$ & $>0,05$ & $<0,001$ & $>0,05$ & $>0,05$ & $>0,05$ & & & & \\
\hline & QUE & $<0,001$ & $>0,05$ & $>0,05$ & $<0,001$ & $>0,05$ & $>0,05$ & $>0,05$ & $>0,05$ & & & \\
\hline \multirow{3}{*}{ B83 } & $\mathrm{CO}_{2}$ & $>0,05$ & $>0,05$ & $>0,05$ & $>0,05$ & $>0,05$ & $>0,05$ & $<0,001$ & $<0,001$ & $<0,001$ & & \\
\hline & NOR & $>0,05$ & $>0,05$ & $>0,05$ & $>0,05$ & $>0,05$ & $>0,05$ & $>0,05$ & $>0,05$ & $>0,05$ & $>0,05$ & \\
\hline & QUE & $>0,05$ & $>0,05$ & $>0,05$ & $>0,05$ & $>0,05$ & $>0,05$ & $>0,05$ & $>0,05$ & $>0,05$ & $>0,05$ & $>0,05$ \\
\hline
\end{tabular}

${ }^{1}$ Stonebrink; ${ }^{2}$ Löwenstein-Jensen com piruvato; ${ }^{3}$ Middlebrook $7 \mathrm{H} 11 ;{ }^{4}$ Ágar sangue tuberculose; ${ }^{5}$ Atmosfera com $10 \%$ de CO2; ${ }^{6}$ Atmosfera ambiente; ${ }^{7}$ Algodão queimado. 
Tabela 41 - Soma de ranks do número de UFC aos 90 dias de incubação, segundo os meios de cultura e as condições de incubação - São Paulo - 2010

\begin{tabular}{c|c|c}
\hline \multicolumn{3}{|c}{ 90dias } \\
\hline meios de cultura & condição de incubação & Soma dos ranks \\
\hline Sto $^{1}$ & $\mathrm{CO}_{2}{ }^{2}$ & 379,5 \\
B83 $^{2}$ & $\mathrm{CO}_{2}$ & 379 \\
LJp $^{3}$ & $\mathrm{CO}_{2}$ & 359 \\
LJp & QUE $^{7}$ & 318,5 \\
Sto & NOR $^{6}$ & 315,5 \\
B83 & NOR $^{2}$ & 311 \\
LJp & NOR & 308,5 \\
Sto & QUE & 302,5 \\
B83 & QUE & 290,5 \\
$7 H 11^{4}$ & NOR & 216 \\
$7 H 11$ & CO & 211,5 \\
$7 H 11$ & QUE & 196,5 \\
\hline
\end{tabular}

${ }^{1}$ Stonebrink; ${ }^{2}$ Ágar sangue tuberculose; ${ }^{3}$ Löwenstein-Jensen com piruvato; ${ }^{4}$ Middlebrook 7H11; ${ }^{5}$ Atmosfera com $10 \%$ de CO2; ${ }^{6}$ Atmosfera ambiente; ${ }^{7}$ Algodão queimado. 
Tabela 42 - Valores de "p” resultantes da comparação do número de UFC aos 90 dias de incubação, segundo os meios de cultura e as condições de incubação - São Paulo 2010

\begin{tabular}{|c|c|c|c|c|c|c|c|c|c|c|c|c|}
\hline \multicolumn{13}{|c|}{90 dias } \\
\hline \multirow{2}{*}{\multicolumn{2}{|c|}{ variáveis }} & \multicolumn{11}{|c|}{ meios de cultura } \\
\hline & & \multicolumn{3}{|c|}{ Sto $^{1}$} & \multicolumn{3}{|c|}{$\mathrm{LJp}^{2}$} & \multicolumn{3}{|c|}{$7 \mathrm{H} 11^{3}$} & \multicolumn{2}{|c|}{$\mathrm{B} 83^{4}$} \\
\hline meios de cultura & condição de incubação & $\mathrm{CO}_{2}^{5}$ & $\mathrm{NOR}^{6}$ & $\mathrm{QUE}^{7}$ & $\mathrm{CO}_{2}$ & NOR & QUE & $\mathrm{CO}_{2}$ & NOR & QUE & $\mathrm{CO}_{2}$ & NOR \\
\hline \multirow{2}{*}{ Sto } & NOR & $>0,05$ & & & & & & & & & & \\
\hline & QUE & $>0,05$ & $>0,05$ & & & & & & & & & \\
\hline \multirow{3}{*}{ LJp } & $\mathrm{CO}_{2}$ & $>0,05$ & $>0,05$ & $>0,05$ & & & & & & & & \\
\hline & NOR & $>0,05$ & $>0,05$ & $>0,05$ & $>0,05$ & & & & & & & \\
\hline & QUE & $>0,05$ & $>0,05$ & $>0,05$ & $>0,05$ & $>0,05$ & & & & & & \\
\hline \multirow{3}{*}{$7 \mathrm{H} 11$} & $\mathrm{CO}_{2}$ & $<0,001$ & $>0,05$ & $>0,05$ & $<0,01$ & $>0,05$ & $>0,05$ & & & & & \\
\hline & NOR & $<0,001$ & $>0,05$ & $>0,05$ & $<0,01$ & $>0,05$ & $>0,05$ & $>0,05$ & & & & \\
\hline & QUE & $<0,001$ & $<0,05$ & $>0,05$ & $<0,001$ & $>0,05$ & $<0,05$ & $>0,05$ & $>0,05$ & & & \\
\hline \multirow{3}{*}{ B83 } & $\mathrm{CO}_{2}$ & $>0,05$ & $>0,05$ & $>0,05$ & $>0,05$ & $>0,05$ & $>0,05$ & $<0,001$ & $<0,001$ & $<0,001$ & & \\
\hline & NOR & $>0,05$ & $>0,05$ & $>0,05$ & $>0,05$ & $>0,05$ & $>0,05$ & $>0,05$ & $>0,05$ & $>0,05$ & $>0,05$ & \\
\hline & QUE & $>0,05$ & $>0,05$ & $>0,05$ & $>0,05$ & $>0,05$ & $>0,05$ & $>0,05$ & $>0,05$ & $>0,05$ & $>0,05$ & $>0,05$ \\
\hline
\end{tabular}

${ }^{1}$ Stonebrink; ${ }^{2}$ Löwenstein-Jensen com piruvato; ${ }^{3}$ Middlebrook $7 \mathrm{H} 11 ;{ }^{4}$ Ágar sangue tuberculose; ${ }^{5}$ Atmosfera com $10 \%$ de CO2; ${ }^{6}$ Atmosfera ambiente; ${ }^{7}$ Algodão queimado. 


\section{DISCUSSÃO}

Em relação aos dados consolidados para os meios de cultura, o Ágar Sangue Tuberculose, ou B83, apresentou as maiores proporções de sucesso no isolamento aos 30 dias de incubação, seguido pelo meio de Stonebrink (Tabelas 1 e 2). Porém, aos 60 e 90 dias, não houve diferença estatística entre os meios B83, Stonebrink e Löwenstein-Jensen com piruvato (Tabelas 3 a 6 e Gráfico 1).

Corner e Nicolacopoulos (1988) utilizaram a suspensão de apenas duas cepas de $M$. bovis, uma laboratorial (AN5) e uma isolada de lesão em linfonodo bovino, e obtiveram uma proporção de isolados maior em B83, após 90 dias de incubação, seguido de LöwensteinJensen com piruvato, Stonebrink e Middlebrook 7H11 modificado com adição de antibióticos, cujo protocolo foi descrito por Gallagher e Horwill (1977).

Cousins, Francis e Gow (1989) também observaram maior proporção de isolados, após 60 dias de incubação, nos meios B83 e Stonebrink com concentração de verde de malaquita reduzida em três vezes, de 0,066 a $0,021 \%$. Entre esses meios não houve diferença significante entre as proporções de sucesso no isolamento, não obstante em 20 oportunidades tenha ocorrido crescimento apenas no B83 e em sete apenas no Stonebrink.

A mesma situação foi observada por Birn (1965), entre uma modificação do meio de Tarshis com sangue ovino e Stonebrink, e pelo presente estudo, no qual sete amostras apresentaram crescimento apenas no meio Stonebrink, quatro apenas no B83 e cinco foram detectadas apenas por Löwenstein-Jensen com piruvato.

Em relação ao tempo transcorrido até o aparecimento das primeiras colônias, no presente estudo os melhores resultados foram observados para os meios B83 (média de 30 dias) e Stonebrink (média de 37 dias) (Tabelas 7 e 8). Resultado semelhante foi encontrado por Corner (1994), em estudos com 491 amostras coletadas de bovinos reatores a tuberculina, com a média de tempo do aparecimento da primeira colônia de 27 dias para B83 e 36 dias para Stonebrink.

Vários autores constataram que o aparecimento das primeiras colônias de M. bovis foi mais precoce nos meios a base de ágar do que nos meios a base de ovo (BIRN, 1965; GALLAGHER; HORWILL, 1977; CORNER; NICOLACOPOULOS, 1988; COUSINS; FRANCIS; GOW, 1989), com aproximadamente uma semana de diferença (COUSINS; FRANCIS; GOW, 1989) 
Em relação ao número de UFC de $M$. bovis, não houve diferença entre os meios B83, Stonebrink e Löwenstein-Jensen com piruvato, que foram superiores ao 7H11 (Tabelas 9 a 14). Resultados semelhantes foram observados por Cousins, Francis e Gow (1989). Porém, Gallagher e Horwill (1977) observaram um crescimento mais abundante em 7H11 adicionado com antibióticos, quando comparado aos meios de Tarshis (ágar sangue precursor do B83), Löwenstein-Jensen com piruvato e Stonebrink.

Em relação aos dados consolidados para as condições de incubação, o presente estudo constatou que o acréscimo de $10 \%$ de $\mathrm{CO}_{2}$ na atmosfera diminuiu o tempo necessário para o aparecimento das primeiras colônias (Tabelas 21 e 22), com médias de 31 dias para incubação em atmosfera de $10 \%$ de $\mathrm{CO}_{2}, 38$ para o fechamento do tubo com algodão queimado e 40 para incubação em estufa normal. Além disso, aumentou o número de UFC isoladas aos 30, 60 e 90 dias de incubação (Tabelas 23 a 28) e a proporção de sucesso no isolamento aos 30 dias, mas não aos 60 e 90 dias de incubação (Tabelas 15 a 20 e Gráfico 2).

Embora o M. bovis seja classificado como microaerófilo e ter o aumento da concentração de $\mathrm{CO}_{2}$, na atmosfera de incubação, preconizado como fator de crescimento, são raros os experimentos que testaram essa hipótese. Curiosamente, a característica microaerófila foi atribuída ao M. bovis apenas pela observação do seu crescimento profundo em meio semisólido (MARKS, 1972; MARKS, 1976; COLLINS; YATES; GRANGE, 1982). Existem estudos conduzidos com acréscimo de $\mathrm{CO}_{2}$ (CORNER; NICOLACOPOULOS, 1988; CORNER; TRAJSTMAN; 1988), e outros em atmosfera normal (COUSINS; FRANCIS; GOW, 1989), sempre relatando êxito no isolamento. Apenas Corner (1994), em estudo com 43 amostras, relatou que a inclusão de $5 \%$ de $\mathrm{CO}_{2}$ na atmosfera de incubação não teve efeito na taxa de crescimento ou no número de colônias de $M$. bovis no primo isolamento, e que concentrações acima de $5 \%$ inibiram o crescimento.

A análise dos dados não consolidados mostrou que o acréscimo de $\mathrm{CO}_{2}$ na atmosfera de incubação foi importante para os meios de cultura a base de ovo apenas no seu início, ou seja, aos 30 dias (Tabelas 29 e 30), diminuindo ou mesmo desaparecendo com o evoluir da incubação (Tabelas 29 a 34 e 37 a 42). Esse comportamento não foi observado nos meios a base de ágar, para os quais a incubação em atmosfera de $10 \%$ de $\mathrm{CO}_{2}$ não influenciou nenhum parâmetro estudado (Tabelas 29 a 34 e 37 a 42). Assim, os resultados do presente experimento concordam apenas com a primeira das afirmações de Corner, Lund e Kyrwult ${ }^{1}$ (apud 
CORNER; NICOLACOPOULOS, 1988, p. 203), de que a presença de $\mathrm{CO}_{2}(5 \%)$ aumenta o crescimento de $M$. bovis em meios a base de ovo e diminui em meios a base de ágar.

Os meios de cultura Stonebrink, Löwenstein-Jensen com piruvato e B83 apresentaram performances iguais em relação às variáveis estudadas e sempre superiores à do meio Middlebrook 7H11 (Tabelas 31 a 42). Isso pode ser explicado pela presença de glicerol na formulação desse último, que é tóxica para o M. bovis (KEATING et al., 2005). Conflitando com esses resultados, Gallagher e Horwill (1977), Corner e Nicolacopoulos (1988) e Corner e Trajstman (1988), reportaram um bom desempenho do 7H11 no primo isolamento de $M$. bovis. Robbe-Austerman, Bravo e Harris (2009) utilizaram variações do 7H11 para o mesmo propósito e verificaram bons resultados.

Assim, é importante ressaltar que o meio Middlebrook 7H11, para os isolados brasileiros de $M$. bovis do presente estudo, apresentou os piores resultados, além de ser o mais caro dos quatro meios de cultura ensaiados (em Janeiro/2009: R $\$ 5,87 /$ tubo, contra $\mathrm{R} \$ 0,53 /$ tubo para B83 e R \$0,11/tubo para Stonebrink e Löwenstein-Jensen com piruvato).

Adicionalmente, os melhores resultados dos meios Stonebrink, Löwenstein-Jensen com piruvato e $\mathrm{B} 83$ sempre apareceram na incubação com atmosfera de $10 \%$ de $\mathrm{CO}_{2}$ (Tabelas 35, 37, 39 e 41).

Pela análise dos resultados da proporção de sucesso de isolamento para os dados não consolidados (Tabelas 31 e 33), a dilatação do tempo de incubação de 60 para 90 dias levou a um pequeno ganho de sensibilidade, especialmente para os meios a base de ovo.

Corner e Nicolacopoulos (1988) sugeriram o uso de mais de um tipo de meio de cultura para o primo isolamento de $M$. bovis, pois as colônias aparecem mais rápido em meios a base de ágar, mas há maior crescimento em meios a base de ovo. Segundo Cousins, Francis e Gow (1989), dois tubos de B83 e dois tubos de meio a base de ovo são recomendados para o isolamento de rotina, pois o meio ágar sangue é simples e barato, e o fundo vermelho escuro facilita a identificação de colônias. Porém, no presente estudo, as colônias apresentaram-se translúcidas e levemente escurecidas em um fundo de cor marrom do meio B83 (Foto 1), o que, juntamente com os debris do inóculo, dificultou a observação.

Considerando que os números brutos do presente estudo mostraram melhores resultados sempre para os meios Stonebrink e B83 incubados em atmosfera com $\mathrm{CO}_{2}$ e que em sete oportunidades houve isolamento de M. bovis apenas no meio de Stonebrink e em quatro apenas no B83, a melhor estratégia de primo isolamento de $M$. bovis é a utilização desses dois meios de cultura em paralelo, incubados por 90 dias a $37^{\circ} \mathrm{C}$ em atmosfera com acréscimo de $\mathrm{CO}_{2}$. 


\section{CONCLUSÕES}

Através dos resultados obtidos, podemos concluir que:

- o acréscimo de $\mathrm{CO}_{2}$ na atmosfera de incubação foi importante para os meios de cultura a base de ovo apenas no início da incubação (30 dias), diminuindo ou mesmo desaparecendo com o passar do tempo (60 e 90 dias);

- a incubação em atmosfera de $10 \%$ de $\mathrm{CO}_{2}$ não influenciou o isolamento de $M$. bovis em meios a base de ágar;

- os meios de cultura Stonebrink, Löwenstein-Jensen com piruvato e B83 apresentaram performances iguais e sempre superiores à do meio Middlebrook 7H11;

- a dilatação do tempo de incubação de 60 para 90 dias levou a um pequeno ganho de sensibilidade, especialmente para os meios a base de ovo;

- a melhor estratégia de primo isolamento de $M$. bovis é a utilização dos meios Stonebrink e B83 em paralelo, incubados por 90 dias a $37^{\circ} \mathrm{C}$ em atmosfera com acréscimo de $\mathrm{CO}_{2}$. 


\section{REFERÊNCIAS}

AMBROSIO, S. R.; OLIVEIRA, E. M. D.; RODRIGUEZ, C. A. R.; FERREIRA NETO, J. S.; AMAKU, M. Comparison of three decontamination methods for Mycobacterium bovis isolation. Brazilian Journal of Microbiology, Rio de Janeiro, v. 39, n. 2, p. 241-244, 2008.

BEAM, R. E.; KUBICA, G. P. Stimulatory effects of carbon dioxide on the primary isolation of tubercle bacilli on agar-containing medium. The American Journal of Clinical Pathology, Baltimore, v. 50, n. 3, p. 395-397, 1968.

BEMER-MELCHIOR, P.; DRUGEON, H. B. Inactivation of Mycobacterium tuberculosis for DNA typing analysis. Journal of Clinical microbiology, Washington, v. 37, n. 7, p. 23502351, 1999.

BIRN, K. J. Blood medium for the isolation of tubercle bacilli. British Veterinary Journal, London, v. 121, n. 9, p. 437-441, 1965.

BRASIL. Ministério da Agricultura, do Abastecimento e da Reforma Agrária. Portaria $\mathrm{n}^{\mathrm{o}} 101$, de 17.08.93. Métodos de Análise Microbiológica para Alimentos. 1991/1992 - 2. rev.

Brasília: Ministério da Agricultura, do Abastecimento e da Reforma Agrária, 1993. 136p.

CENTRO PANAMERICANO DE ZOONOSIS. Tuberculosis. Bacteriologia de la tuberculosis: el cultivo del Mycobacterium tuberculosis. Buenos Aires: CPZ, 1985. (Nota técnica, n. 27).

CHAUHAN, M. M.; SREENIVAS, T. R.; CHAUDHURI, K. Effect of carbon dioxide on the primary isolation of mycobacteria. Indian Journal of Tuberculosis, New Delhi, v. 38, n. 2, p. 81-85, 1991.

COLLINS, C. H.; YATES, M. D.; GRANGE, J. M. Subdivision of Mycobaterium tuberculosis into five variants for epidemiological purposes: methods and nomenclature. The Journal of Hygiene, London, v. 89, n. 2, p. 235-242, 1982.

COLLINS, C. H.; GRANGE, J. M. A Review The bovine tubercle bacillus. Journal of Applied Bacteriology, Oxford, v. 55, n. 1, p. 13-29, 1983.

CORNER, L. A. Post mortem diagnosis of Mycobacterium bovis infection in cattle.

Veterinary Microbiology, Amsterdam, v. 40, n. 1-2, p. 53-63, 1994. 
CORNER, L. A.; NICOLACOPOULOS, C. Comparison of media used for the primary isolation of Mycobacterium bovis by veterinary and medical diagnostic laboratories.

Australian Veterinary Journal, Sydney, v. 65, n. 7, p. 202-205, 1988.

CORNER, L. A.; TRAJSTMAN, A. C. An evaluation of 1-Hexadecylpyridinium Chloride as a decontaminant in the primary isolation of Mycobacterium bovis from bovine lesions.

Veterinary Microbiology, Amsterdam, v. 18, n. 2, p.127-134, 1988.

COSIVI, O.; GRANGE, J. M.; DABORN, C. J.; RAVIGLIONE, M. C.; FUJIKURA, T.; COUSINS, D.; ROBINSON, R. A.; HUCHZERMEYER, H. F. A. K.; DE KANTOR, I. N.; MESLIN, F. X. Zoonotic tuberculosis due to Mycobacterium bovis in developing countries. Emerging Infectious Diseases, Atlanta, v. 4, n. 1, p. 59-70, 1998.

COUSINS, D. V. Mycobacterium bovis infection and control in domestic livestock. Revue Scientifique et Technique (Internacional Office of Epizootics), Paris, v.20, n. 1, p.71-85, 2001.

COUSINS, D. V.; FRANCIS, B. R.; GOW, B. L. Advantages of a new agar medium in the primary isolation of Mycobacterium bovis. Veterinary Microbiology, Amsterdam, v. 20, n. 1, p. 89-95, 1989.

DAVIES, R. The effect of carbon dioxide on the growth of the tubercle bacillus. The British Journal of Experimental Pathology, London, v. 21, n. 5, p. 243-253, 1940.

GALLAGHER, J.; HORWILL, D. M. A selective oleic acid albumin agar medium for the cultivation of Mycobacterium bovis. The Journal of Hygiene, London, v. 79, n. 1, p. 155160, 1977.

GRANGE, J. M.; COLLINS, J. D.; O’REILLY, L. M.; COSTELLO, E.; YATES, M. D. Identification and characteristics of Mycobacterium bovis isolated from cattle, badgers and deer in the Republic of Ireland. Irish Veterinary Journal, Dublin, v. 43, n. 2, p. 33-35, 1990.

GRANGE, J. M.; YATES, M. D. Zoonotic aspects of Mycobacterium bovis infection. Veterinary Microbiology, Amsterdam, v. 40, n. 1-2, p. 137-151, 1994.

GRUFT, H.; LODER, A. Enhancing effects oh carbon dioxide on the primary isolation of acid-fast bacilli in a modified Lowenstein-Jensen medium. Applied Microbiology, Washington, v. 22, n. 5, p. 944-945, 1971. 
KARLSON, A. G.; LESSEL, E. F. Mycobacterium bovis nom. nov. International Journal of Systematic Bacteriology, Ames, v. 20, n. 3, p. 273-282, 1970.

KEATING, L. A.; WHEELER, P. R.; MANSOOR, H.; INWALD, J. K.; DALE, J.; HEWINSON, R. G.; GORDON, S. V. The pyruvate requirement of some members of the Mycobacterium tuberculosis complex is due to an inactive pyruvate kinase: implications for in vivo growth. Molecular Microbiology, Oxford, v. 56, n. 1, p. 163-174, 2005.

KRASNOW, I.; WAYNE, L. G. Comparison of methods for tuberculosis bacteriology. Applied Microbiology, Washington, v. 18, n. 5, p. 915-917, 1969.

KREMER, K.; VAN SOOLINGEN, D.; FROTHINGHAM, R.; HAAS, W. H.; HERMANS P. W. M.; MARTÍN, C.; PALITTAPONGARNPIM, P.; PLIKAYTIS, B. B.; RILEY, L. W.; YAKRUS, M. A.; MUSSER, J. M.; VAN EMBDEN, J. D. A. Comparison of methods based on different molecular epidemiological markers for typing of Mycobacterium tuberculosis complex strains: interlaboratory study of discriminatory power and reproducibility. Journal of Clinical Microbiology, Washington, v. 37, n. 8, p. 2607-2618, 1999.

LAGE, A. P.; ROXO, E.; MÜLLER, E.; POESTER, F.; CAVALLÉRO, J. C. M.; FERREIRA NETO, J. S.; MOTA, P. M. P. C.; GONÇALVES, V. S. P. Programa Nacional de Controle e Erradicação da Brucelose e da Tuberculose Animal (PNCEBT). Brasília: MAPA, 2006. 184p. (manual técnico).

LESSLIE, I. W. A comparison of biological and some cultural methods for the primary isolation of Mycobacterium tuberculosis. Journal of Comparative Pathology, London, v.69, n. 1, p.1-10, 1959.

MARKS, J. Classification of mycobacteria in relation to clínical significance. Tubercle, London, v. 53, n. 4, p. 259-264, 1972.

MARKS, J. A system for the examination of tubercle bacilli and other mycobacteria. Tubercle, London, v. 57, n. 3, p. 207-225, 1976.

MODA, G.; DABORN, C. J.; GRANGE, J. M.; COSIVI, O. The zoonotic importance of Mycobacterium bovis. Tubercle and Lung Disease, Edinburgh, v. 77, n. 2, p. 103-108, 1996.

MORRIS, R. S.; PFEIFFER, D. U.; JACKSON, R. The epidemiology of Mycobacterium bovis infections. Veterinary Microbiology, Amsterdam, v. 40, n. 1-2, p. 153-177, 1994. 
O'REILLY, L. M.; DABORN, C. J. The epidemiology of Mycobacterium bovis infections in animals and man: a review. Tubercle and Lung Disease, Edinburgh, v. 76, p. 1-46, 1995. Supplement 1.

ORGANIZAÇÃO MUNDIAL DA SAÚDE ANIMAL. OIE. Bovine tuberculosis. In:

Manual of Diagnostics Tests and Vaccines for Terrestrial Animals. 2010. v. 2, pt. 2, sec. 2.4, chap. 2.4.7. Disponível em:

<http://www.oie.int/fileadmin/Home/eng/Health_standards/tahm/2.04.07_BOVINE_TB.pdf>. Acesso em: 28 fev. 2011.

POLLOCK, J. M.; RODGERS, J. D.; WELSH, M. D.; McNAIR, J. Pathogenesis of bovine tuberculosis: The role of experimental models of infection. Veterinary Microbiology, Amsterdam, v. 112, n. 2-4, p. 141-150, 2006.

ROBBE-AUSTERMAN, S.; BRAVO, D.; HARRIS, B. Tissue processing and culture media evaluation for the detection of Mycobacterium bovis. In: CONFERENCE, 5., 2009, Wellington. Abstract... New Zealand: Hosted by Animal Health Board, 2009. p. 39.

ROCKWELL, G. E.; HIGHBERGER, J. H. Carbon dioxide as a factor in the growth of the tubercle bacillus and of other acidfast organisms. Journal of Infectious Diseases, Chicago, v. 38, n. 1, p. 92-100, 1926.

SAINT-EXUPÉRY, A. O pequeno príncipe. 48. ed. Rio de Janeiro: Agir, 2009. 96 p.

SCHAEFER, W. B. Growth requirements of dysgonic and eugonic strains of Mycobacterium tuberculosis var. bovis. The Journal of Experimental Medicine, New York, v. 96, n. 3, p. 207-219, 1952.

SCHAEFER, W. B.; COHN, M. L.; MIDDLEBROOK, G. The roles of biotin and carbon dioxide in the cultivation of Mycobacterium tuberculosis. Journal of Bacteriology, Baltimore, v. 69, n. 6, p. 706-712, 1955.

SMITH, T. A comparative study of bovine tubercle bacilli and of human bacilli from sputum. The Journal of Experimental Medicine, New York, v. 3, n. 4-5, p. 451-511, 1898.

SPOLIGOTYPING. A PCR-based method to simultaneously detect and type Mycobacterium tuberculosis complex bacteria. [200-?]. Disponível em: <http://www.moleculartb.org/gb/pdf/protocols/SpoligoManual.pdf>. Acesso em: 04 abr. 2011. 
TARSHIS, M. S. Blood mediums for cultivation of Mycobacterium tuberculosis. V. Results with agar-agar basal medium and varying concentrations of blood, glycerine and penicillin. American Journal of Clinical Pathology, Philadelphia, v. 23, n. 7, p. 661-670, 1953.

TELENTI, A.; MARCHESI, F.; BALZ, M.; BALLY, F.; BÖTTGER, E. C.; BODMER, T. Rapid identification of mycobacteria to the species level by polymerase chain reaction and restriction enzyme analysis. Journal of Clinical Microbiology, Washington, v. 31, n. 2, p. 175-178, 1993.

WHITCOMB, F. C.; FOSTER, M. C.; DUKES, C. D. Increased carbon dioxide tension and the primary isolation of mycobacteria. The American Review of Respiratory Disease, Baltimore, v. 86, p. 584-586, 1962 


\section{APÊNDICE A}

Obtenção de isolado de Mycobacterium bovis, segundo os meios de cultura e as condições de incubação.

\begin{tabular}{|c|c|c|c|c|c|c|c|c|c|c|c|c|}
\hline \multirow{4}{*}{ repetições } & \multicolumn{12}{|c|}{ meios de cultura } \\
\hline & \multicolumn{3}{|c|}{ Sto $^{1}$} & \multicolumn{3}{|c|}{$\mathrm{LJp}^{2}$} & \multicolumn{3}{|c|}{$7 \mathrm{H} 11^{3}$} & \multicolumn{3}{|c|}{ B83 ${ }^{4}$} \\
\hline & \multicolumn{3}{|c|}{ condição de incubação } & \multicolumn{3}{|c|}{ condição de incubação } & \multicolumn{3}{|c|}{ condição de incubação } & \multicolumn{3}{|c|}{ condição de incubação } \\
\hline & $\mathrm{CO}_{2}{ }^{5}$ & $\mathrm{NOR}^{6}$ & $\mathrm{QUE}^{7}$ & $\mathrm{CO}_{2}$ & NOR & QUE & $\mathrm{CO}_{2}$ & NOR & QUE & $\mathrm{CO}_{2}$ & NOR & QUE \\
\hline 1 & $\mathrm{P}^{8}$ & $-{ }^{9}$ & - & - & - & $\mathrm{P}$ & - & - & - & - & $P$ & - \\
\hline 2 & - & - & - & - & $\mathrm{P}$ & - & - & - & - & - & - & - \\
\hline 3 & $\mathrm{P}$ & - & - & $\mathrm{P}$ & - & $\mathrm{P}$ & - & $\mathrm{P}$ & $\mathrm{P}$ & - & $\mathrm{P}$ & - \\
\hline 4 & - & - & - & - & $\mathrm{P}$ & - & - & - & - & - & - & - \\
\hline 5 & - & $P$ & - & $P$ & - & - & - & - & - & - & - & - \\
\hline 6 & - & $\mathrm{P}$ & $\mathrm{P}$ & $\mathrm{P}$ & - & $\mathrm{P}$ & $\mathrm{P}$ & - & - & $\mathrm{P}$ & $\mathrm{P}$ & - \\
\hline 7 & $\mathrm{P}$ & - & - & - & - & - & - & - & - & - & - & - \\
\hline 8 & $\mathrm{P}$ & $\mathrm{P}$ & $\mathrm{P}$ & $\mathrm{P}$ & $\mathrm{P}$ & $\mathrm{P}$ & $\mathrm{P}$ & $\mathrm{P}$ & $\mathrm{P}$ & $\mathrm{P}$ & $\mathrm{P}$ & $\mathrm{P}$ \\
\hline 9 & $\mathrm{P}$ & $\mathrm{P}$ & $\mathrm{P}$ & $\mathrm{P}$ & $\mathrm{P}$ & $\mathrm{P}$ & - & $\mathrm{P}$ & $\mathrm{P}$ & $\mathrm{P}$ & $\mathrm{P}$ & $\mathrm{P}$ \\
\hline 10 & $\mathrm{P}$ & - & $\mathrm{P}$ & $\mathrm{P}$ & $\mathrm{P}$ & $\mathrm{P}$ & $\mathrm{P}$ & - & $\mathrm{P}$ & $\mathrm{P}$ & $\mathrm{P}$ & $\mathrm{P}$ \\
\hline 11 & - & - & - & $\mathrm{P}$ & - & - & - & - & - & - & - & - \\
\hline 12 & $\mathrm{P}$ & - & - & - & $\mathrm{P}$ & - & - & $\mathrm{P}$ & - & - & $\mathrm{P}$ & - \\
\hline 13 & - & - & - & - & - & - & - & - & - & - & $\mathrm{P}$ & - \\
\hline 14 & $\mathrm{P}$ & $\mathrm{P}$ & - & $\mathrm{P}$ & $\mathrm{P}$ & $\mathrm{P}$ & - & - & - & $\mathrm{P}$ & - & - \\
\hline 15 & $\mathrm{P}$ & - & $\mathrm{P}$ & $\mathrm{P}$ & - & $\mathrm{P}$ & - & - & - & - & - & - \\
\hline 16 & - & $\mathrm{P}$ & - & - & - & $\mathrm{P}$ & - & - & - & - & - & - \\
\hline 17 & $\mathrm{P}$ & $\mathrm{P}$ & - & - & - & $\mathrm{P}$ & - & - & - & - & - & - \\
\hline 18 & - & $\mathrm{P}$ & - & $\mathrm{P}$ & - & - & - & - & - & $\mathrm{P}$ & - & - \\
\hline 19 & $\mathrm{P}$ & $\mathrm{P}$ & $\mathrm{P}$ & $\mathrm{P}$ & $\mathrm{P}$ & $\mathrm{P}$ & $\mathrm{P}$ & - & - & $\mathrm{P}$ & $\mathrm{P}$ & - \\
\hline 20 & - & $\mathrm{P}$ & - & $\mathrm{P}$ & $\mathrm{P}$ & - & - & - & - & $\mathrm{P}$ & $\mathrm{P}$ & - \\
\hline 21 & $\mathrm{P}$ & $\mathrm{P}$ & $\mathrm{P}$ & - & $\mathrm{P}$ & $\mathrm{P}$ & - & - & - & $\mathrm{P}$ & $\mathrm{P}$ & $\mathrm{P}$ \\
\hline 22 & - & - & - & - & $\mathrm{P}$ & - & - & - & - & - & - & - \\
\hline 23 & $\mathrm{P}$ & - & $\mathrm{P}$ & $\mathrm{P}$ & - & $\mathrm{P}$ & - & - & - & - & - & - \\
\hline 24 & $\mathrm{P}$ & $\mathrm{P}$ & $\mathrm{P}$ & $\mathrm{P}$ & $\mathrm{P}$ & $\mathrm{P}$ & $\mathrm{P}$ & - & - & $\mathrm{P}$ & $\mathrm{P}$ & $\mathrm{P}$ \\
\hline 25 & $\mathrm{P}$ & $\mathrm{P}$ & $\mathrm{P}$ & $\mathrm{P}$ & $\mathrm{P}$ & $\mathrm{P}$ & $\mathrm{P}$ & $\mathrm{P}$ & - & $\mathrm{P}$ & $\mathrm{P}$ & $\mathrm{P}$ \\
\hline 26 & - & - & - & $\mathrm{P}$ & - & $\mathrm{P}$ & - & - & - & - & - & - \\
\hline 27 & $\mathrm{P}$ & $\mathrm{P}$ & - & $\mathrm{P}$ & - & $\mathrm{P}$ & - & - & - & $\mathrm{P}$ & - & - \\
\hline 28 & - & $\mathrm{P}$ & $\mathrm{P}$ & - & $\mathrm{P}$ & $\mathrm{P}$ & $\mathrm{P}$ & - & - & $\mathrm{P}$ & $\mathrm{P}$ & $\mathrm{P}$ \\
\hline 29 & $\mathrm{P}$ & $\mathrm{P}$ & $\mathrm{P}$ & $\mathrm{P}$ & $\mathrm{P}$ & $\mathrm{P}$ & - & - & - & $\mathrm{P}$ & $\mathrm{P}$ & $\mathrm{P}$ \\
\hline 30 & $\mathrm{P}$ & $\mathrm{P}$ & $\mathrm{P}$ & $\mathrm{P}$ & $\mathrm{P}$ & $\mathrm{P}$ & - & - & - & $\mathrm{P}$ & $\mathrm{P}$ & - \\
\hline 31 & - & $\mathrm{P}$ & - & - & - & - & - & - & - & - & - & - \\
\hline 32 & - & - & - & - & - & - & - & - & - & $\mathrm{P}$ & $\mathrm{P}$ & - \\
\hline 33 & $\mathrm{P}$ & - & $\mathrm{P}$ & - & $\mathrm{P}$ & $\mathrm{P}$ & - & - & - & $\mathrm{P}$ & $\mathrm{P}$ & $\mathrm{P}$ \\
\hline 34 & $\mathrm{P}$ & $\mathrm{P}$ & $\mathrm{P}$ & $\mathrm{P}$ & $\mathrm{P}$ & $\mathrm{P}$ & $\mathrm{P}$ & $\mathrm{P}$ & - & $\mathrm{P}$ & $\mathrm{P}$ & $\mathrm{P}$ \\
\hline 35 & $\mathrm{P}$ & $\mathrm{P}$ & - & - & - & - & - & - & - & $\mathrm{P}$ & $\mathrm{P}$ & $\mathrm{P}$ \\
\hline 36 & $\mathrm{P}$ & $\mathrm{P}$ & $\mathrm{P}$ & - & - & - & - & - & - & $\mathrm{P}$ & - & $\mathrm{P}$ \\
\hline 37 & $\mathrm{P}$ & $\mathrm{P}$ & $\mathrm{P}$ & $\mathrm{P}$ & $\mathrm{P}$ & $\mathrm{P}$ & $\mathrm{P}$ & - & - & $\mathrm{P}$ & $\mathrm{P}$ & $\mathrm{P}$ \\
\hline 38 & - & $\mathrm{P}$ & $\mathrm{P}$ & $\mathrm{P}$ & $\mathrm{P}$ & $\mathrm{P}$ & - & - & - & $\mathrm{P}$ & - & $\mathrm{P}$ \\
\hline 39 & $\mathrm{P}$ & $\mathrm{P}$ & $\mathrm{P}$ & $\mathrm{P}$ & $\mathrm{P}$ & $\mathrm{P}$ & $\mathrm{P}$ & - & - & $\mathrm{P}$ & $\mathrm{P}$ & $\mathrm{P}$ \\
\hline 40 & $\mathrm{P}$ & $\mathrm{P}$ & $\mathrm{P}$ & $\mathrm{P}$ & $\mathrm{P}$ & $\mathrm{P}$ & - & - & - & $\mathrm{P}$ & $\mathrm{P}$ & $\mathrm{P}$ \\
\hline 41 & $\mathrm{P}$ & - & - & - & - & - & - & - & - & $\mathrm{P}$ & $\mathrm{P}$ & $\mathrm{P}$ \\
\hline 42 & $\mathrm{P}$ & - & - & - & - & - & - & - & - & $\mathrm{P}$ & - & $\mathrm{P}$ \\
\hline 43 & - & - & - & - & - & - & - & - & - & $\mathrm{P}$ & $\mathrm{P}$ & $\mathrm{P}$ \\
\hline 44 & $\mathrm{P}$ & - & - & $\mathrm{P}$ & - & - & - & - & - & $\mathrm{P}$ & $\mathrm{P}$ & $\mathrm{P}$ \\
\hline 45 & $\mathrm{P}$ & $\mathrm{P}$ & $\mathrm{P}$ & - & - & - & $\mathrm{P}$ & - & - & $\mathrm{P}$ & $\mathrm{P}$ & $\mathrm{P}$ \\
\hline 46 & - & - & - & - & - & - & - & - & - & - & - & $\mathrm{P}$ \\
\hline
\end{tabular}

${ }^{1}$ Stonebrink; ${ }^{2}$ Löwenstein-Jensen com piruvato; ${ }^{3}$ Middlebrook $7 \mathrm{H} 11 ;{ }^{4}$ Ágar sangue tuberculose; ${ }^{5}$ Atmosfera com $10 \%$ de CO2; ${ }^{6}$ Atmosfera ambiente; ${ }^{7}$ Algodão queimado; ${ }^{8}$ Positivo; ${ }^{9}$ Negativo 


\section{APÊNDICE B}

Número de UFC de Mycobacterium bovis aos 30 dias de incubação, segundo os meios de cultura e as condições de incubação.

\begin{tabular}{|c|c|c|c|c|c|c|c|c|c|c|c|c|}
\hline \multirow{4}{*}{ repetições } & \multicolumn{12}{|c|}{ meios de cultura } \\
\hline & \multicolumn{3}{|c|}{ Sto $^{1}$} & \multicolumn{3}{|c|}{$\mathrm{LJp}^{2}$} & \multicolumn{3}{|c|}{$7 \mathrm{H} 11^{3}$} & \multicolumn{3}{|c|}{$\mathrm{B}_{8} 3^{4}$} \\
\hline & \multicolumn{3}{|c|}{ condição de incubação } & \multicolumn{3}{|c|}{ condição de incubação } & \multicolumn{3}{|c|}{ condição de incubação } & \multicolumn{3}{|c|}{ condição de incubação } \\
\hline & $\mathrm{CO}_{2}{ }^{5}$ & $\mathrm{NOR}^{6}$ & $\mathrm{QUE}^{7}$ & $\mathrm{CO}_{2}$ & NOR & QUE & $\mathrm{CO}_{2}$ & NOR & QUE & $\mathrm{CO}_{2}$ & NOR & QUE \\
\hline 1 & 2 & 0 & 0 & 0 & 0 & 0 & 0 & 0 & 0 & 0 & 0 & 0 \\
\hline 2 & 0 & 0 & 0 & 0 & 0 & 0 & 0 & 0 & 0 & 0 & 0 & 0 \\
\hline 3 & 1 & 0 & 0 & 2 & 0 & 0 & 0 & 6 & 1 & 0 & 0 & 0 \\
\hline 4 & 0 & 0 & 0 & 0 & 0 & 0 & 0 & 0 & 0 & 0 & 0 & 0 \\
\hline 5 & 0 & 0 & 0 & 0 & 0 & 0 & 0 & 0 & 0 & 0 & 0 & 0 \\
\hline 6 & 0 & 1 & 2 & 0 & 0 & 0 & 2 & 0 & 0 & 1 & 0 & 0 \\
\hline 7 & 1 & 0 & 0 & 0 & 0 & 0 & 0 & 0 & 0 & 0 & 0 & 0 \\
\hline 8 & 4 & 0 & 5 & 1,5 & 0 & 0 & 2 & 2 & 2 & 4 & 2 & 1 \\
\hline 9 & 3 & 0 & 0 & 2 & 0 & 0 & 0 & 3 & 2 & 0 & 2 & 1 \\
\hline 10 & 2 & 0 & 0 & 2 & 0 & 0 & 1 & 0 & 2 & 4 & 1 & 3 \\
\hline 11 & 0 & 0 & 0 & 0 & 0 & 0 & 0 & 0 & 0 & 0 & 0 & 0 \\
\hline 12 & 1 & 0 & 0 & 0 & 0 & 0 & 0 & 8 & 0 & 0 & 0 & 0 \\
\hline 13 & 0 & 0 & 0 & 0 & 0 & 0 & 0 & 0 & 0 & 0 & 1 & 0 \\
\hline 14 & 4 & 2 & 0 & 4 & 0 & 0 & 0 & 0 & 0 & 0 & 0 & 0 \\
\hline 15 & 0,5 & 0 & 0 & 0,5 & 0 & 0 & 0 & 0 & 0 & 0 & 0 & 0 \\
\hline 16 & 0 & 0,5 & 0 & 0 & 0 & 0 & 0 & 0 & 0 & 0 & 0 & 0 \\
\hline 17 & 1 & 0,5 & 0 & 0 & 0 & 0 & 0 & 0 & 0 & 0 & 0 & 0 \\
\hline 18 & 0 & 0 & 0 & 1,5 & 0 & 0 & 0 & 0 & 0 & 0,5 & 0 & 0 \\
\hline 19 & 1 & 0,5 & 0 & 1,5 & 0 & 0 & 0 & 0 & 0 & 1 & 1 & 0 \\
\hline 20 & 0 & 0,5 & 0 & 1 & 0 & 0 & 0 & 0 & 0 & 1 & 0,5 & 0 \\
\hline 21 & 0,5 & 0,5 & 0 & 0 & 0 & 0 & 0 & 0 & 0 & 1 & 0,5 & 0,5 \\
\hline 22 & 0 & 0 & 0 & 0 & 0 & 0 & 0 & 0 & 0 & 0 & 0 & 0 \\
\hline 23 & 1,5 & 0 & 0 & 0,5 & 0 & 0 & 0 & 0 & 0 & 0 & 0 & 0 \\
\hline 24 & 42,5 & 0 & 0,5 & 38,5 & 0 & 0 & 2 & 0 & 0 & 34,5 & 19 & 13,5 \\
\hline 25 & 2,5 & 0 & 0 & 0,5 & 0 & 0 & 0 & 0 & 0 & 7,5 & 5 & 1,5 \\
\hline 26 & 0 & 0 & 0 & 0 & 0 & 0 & 0 & 0 & 0 & 0 & 0 & 0 \\
\hline 27 & 0,5 & 0 & 0 & 1 & 0 & 0 & 0 & 0 & 0 & 0,5 & 0 & 0 \\
\hline 28 & 0 & 0 & 0 & 0 & 0 & 0 & 0 & 0 & 0 & 1,5 & 0,5 & 0,5 \\
\hline 29 & incont $^{8}$ & 0 & 0 & 3 & 0 & 0 & 0 & 0 & 0 & 1,5 & 0,5 & 1 \\
\hline 30 & 4 & 0 & 0 & incont & 0 & 0 & 0 & 0 & 0 & 1 & 0,5 & 0 \\
\hline 31 & 0 & 0 & 0 & 0 & 0 & 0 & 0 & 0 & 0 & 0 & 0 & 0 \\
\hline 32 & 0 & 0 & 0 & 0 & 0 & 0 & 0 & 0 & 0 & 1,5 & 0,5 & 0 \\
\hline 33 & 1 & 0 & 0 & 0 & 0 & 0 & 0 & 0 & 0 & 1 & 0 & 1 \\
\hline 34 & 11 & 0 & 0 & 10 & 0 & 0 & 0 & 0 & 0 & 7,5 & 5,5 & 4 \\
\hline 35 & 0,5 & 1 & 0 & 0 & 0 & 0 & 0 & 0 & 0 & 0,5 & 0 & 1 \\
\hline 36 & 1 & 0,5 & 0 & 0 & 0 & 0 & 0 & 0 & 0 & 1 & 0 & 1 \\
\hline 37 & 41 & 1 & 1 & 33,5 & 0 & 0 & 0 & 0 & 0 & 16 & 5,5 & 5 \\
\hline 38 & 0 & 0 & 0 & 1 & 0 & 0 & 0 & 0 & 0 & 1,5 & 0 & 1,5 \\
\hline 39 & 5,5 & 0 & 0 & 7 & 0 & 0 & 0 & 0 & 0 & 4 & 2 & 1,5 \\
\hline 40 & 2,5 & 0 & 0 & 2 & 0 & 0 & 0 & 0 & 0 & 3 & 0 & 1 \\
\hline 41 & 0 & 0 & 0 & 0 & 0 & 0 & 0 & 0 & 0 & 0 & 0 & 0 \\
\hline 42 & 0 & 0 & 0 & 0 & 0 & 0 & 0 & 0 & 0 & 0 & 0 & 0 \\
\hline 43 & 0 & 0 & 0 & 0 & 0 & 0 & 0 & 0 & 0 & 2 & 1 & 2 \\
\hline 44 & 34,5 & 0 & 0 & 0 & 0 & 0 & 0 & 0 & 0 & 130 & 50,5 & 100 \\
\hline 45 & 1 & 0 & 0 & 0 & 0 & 0 & 0 & 0 & 0 & 4,5 & 1,5 & 1 \\
\hline 46 & 0 & 0 & 0 & 0 & 0 & 0 & 0 & 0 & 0 & 0 & 0 & 0,5 \\
\hline
\end{tabular}

${ }^{1}$ Stonebrink; ${ }^{2}$ Löwenstein-Jensen com piruvato; ${ }^{3}$ Middlebrook $7 \mathrm{H} 11 ;{ }^{4}$ Ágar sangue tuberculose; ${ }^{5}$ Atmosfera com $10 \%$ de CO2; ${ }^{6}$ Atmosfera ambiente;

${ }^{7}$ Algodão queimado; ${ }^{8}$ Incontável. 


\section{APÊNDICE C}

Número de UFC de Mycobacterium bovis aos 60 dias de incubação, segundo os meios de cultura e as condições de incubação.

\begin{tabular}{|c|c|c|c|c|c|c|c|c|c|c|c|c|}
\hline \multirow{4}{*}{ repetições } & \multicolumn{12}{|c|}{ meios de cultura } \\
\hline & \multicolumn{3}{|c|}{ Sto $^{1}$} & \multicolumn{3}{|c|}{$\mathrm{LJp}^{2}$} & \multicolumn{3}{|c|}{$7 \mathrm{H} 11^{3}$} & \multicolumn{3}{|c|}{$\mathrm{B}_{8} 3^{4}$} \\
\hline & \multicolumn{3}{|c|}{ condição de incubação } & \multicolumn{3}{|c|}{ condição de incubação } & \multicolumn{3}{|c|}{ condição de incubação } & \multicolumn{3}{|c|}{ condição de incubação } \\
\hline & $\mathrm{CO}_{2}{ }^{5}$ & $\mathrm{NOR}^{6}$ & $\mathrm{QUE}^{7}$ & $\mathrm{CO}_{2}$ & NOR & QUE & $\mathrm{CO}_{2}$ & NOR & QUE & $\mathrm{CO}_{2}$ & NOR & QUE \\
\hline 1 & 2 & 0 & 0 & 0 & 0 & 1 & 0 & 0 & 0 & 0 & 1 & 0 \\
\hline 2 & 0 & 0 & 0 & 0 & 1 & 0 & 0 & 0 & 0 & 0 & 0 & 0 \\
\hline 3 & 1 & 0 & 0 & incont $^{8}$ & 0 & 1 & 0 & 6 & 8 & 0 & 2 & 0 \\
\hline 4 & 0 & 0 & 0 & 0 & 1 & 0 & 0 & 0 & 0 & 0 & 0 & 0 \\
\hline 5 & 0 & 0 & 0 & 2 & 0 & 0 & 0 & 0 & 0 & 0 & 0 & 0 \\
\hline 6 & 0 & 1 & 2 & 1 & 0 & 1 & 2 & 0 & 0 & 1 & 1 & 0 \\
\hline 7 & 1 & 0 & 0 & 0 & 0 & 0 & 0 & 0 & 0 & 0 & 0 & 0 \\
\hline 8 & 4 & 3,5 & 5 & 5 & 3 & 3 & 3 & 2 & 2 & 14 & 2,5 & 1 \\
\hline 9 & 3 & 1 & 1 & incont & 1,5 & 1,5 & 0 & 3 & 2 & 3 & 2 & 1 \\
\hline 10 & 2,5 & 0 & 2 & 4,5 & 1 & 1,5 & 1 & 0 & 2 & incont & 1 & 3 \\
\hline 11 & 0 & 0 & 0 & 0 & 0 & 0 & 0 & 0 & 0 & 0 & 0 & 0 \\
\hline 12 & 1 & 0 & 0 & 0 & 1 & 0 & 0 & 9 & 0 & 0 & 1 & 0 \\
\hline 13 & 0 & 0 & 0 & 0 & 0 & 0 & 0 & 0 & 0 & 0 & 1 & 0 \\
\hline 14 & 4 & 3 & 0 & 5 & incont & 1 & 0 & 0 & 0 & 1 & 0 & 0 \\
\hline 15 & 0,5 & 0 & 0,5 & 0,5 & 0 & 0,5 & 0 & 0 & 0 & 0 & 0 & 0 \\
\hline 16 & 0 & 0,5 & 0 & 0 & 0 & 0,5 & 0 & 0 & 0 & 0 & 0 & 0 \\
\hline 17 & 1 & 0,5 & 0 & 0 & 0 & 0,5 & 0 & 0 & 0 & 0 & 0 & 0 \\
\hline 18 & 0 & 0,5 & 0 & 1,5 & 0 & 0 & 0 & 0 & 0 & 0,5 & 0 & 0 \\
\hline 19 & 1 & 1 & 2 & 2 & 0,5 & 1 & 0,5 & 0 & 0 & 1 & 4 & 0 \\
\hline 20 & 0 & 2,5 & 0 & 1,5 & 1,5 & 0 & 0 & 0 & 0 & 1 & 1 & 0 \\
\hline 21 & 0,5 & 0,5 & 0,5 & 0 & 0,5 & 0 & 0 & 0 & 0 & 1 & 0,5 & 1 \\
\hline 22 & 0 & 0 & 0 & 0 & 0,5 & 0 & 0 & 0 & 0 & 0 & 0 & 0 \\
\hline 23 & 2 & 0 & 0,5 & 0,5 & 0 & 0,5 & 0 & 0 & 0 & 0 & 0 & 0 \\
\hline 24 & 43,5 & 24 & 34 & 40,5 & incont & 37,5 & 7 & 0 & 0 & 35,5 & 24,5 & 16 \\
\hline 25 & 3 & 5 & 1 & 2 & 0,5 & 0,5 & 0,5 & 1,5 & 0 & 7,5 & 6 & 1,5 \\
\hline 26 & 0 & 0 & 0 & 0,5 & 0 & 0,5 & 0 & 0 & 0 & 0 & 0 & 0 \\
\hline 27 & 0,5 & 1 & 0 & 1 & 0 & 0,5 & 0 & 0 & 0 & 0,5 & 0 & 0 \\
\hline 28 & 0 & 1 & 1,5 & 0 & 0 & 0,5 & 0,5 & 0 & 0 & 1,5 & 0,5 & 1,5 \\
\hline 29 & incont & 1 & 1 & 3 & 2 & 0,5 & 0 & 0 & 0 & 1,5 & 1 & 1 \\
\hline 30 & 4 & 0,5 & 1 & incont & 0,5 & 1 & 0 & 0 & 0 & 1 & 0,5 & 0 \\
\hline 31 & 0 & 0,5 & 0 & 0 & 0 & 0 & 0 & 0 & 0 & 0 & 0 & 0 \\
\hline 32 & 0 & 0 & 0 & 0 & 0 & 0 & 0 & 0 & 0 & 1,5 & 0,5 & 0 \\
\hline 33 & 1 & 0 & 0,5 & 0 & 0 & 0 & 0 & 0 & 0 & 1 & 0,5 & 1 \\
\hline 34 & 12 & 5,5 & 7 & 10 & 8,5 & 9 & 2 & 1,5 & 0 & 7,5 & 5,5 & 4 \\
\hline 35 & 0,5 & 5,5 & 0 & 0 & 0 & 0 & 0 & 0 & 0 & 0,5 & 0,5 & 1 \\
\hline 36 & 1 & 0,5 & 0 & 0 & 0 & 0 & 0 & 0 & 0 & 1 & 0 & 1 \\
\hline 37 & 43,5 & 17 & 25,5 & 34,5 & 18 & 29 & 0,5 & 0 & 0 & 18,5 & 18 & 12 \\
\hline 38 & 0 & 0 & 1 & 1 & 1,5 & 1 & 0 & 0 & 0 & 1,5 & 0 & 1,5 \\
\hline 39 & 6 & 2,5 & 4 & 7 & 6 & 36 & 0,5 & 0 & 0 & 4 & 2 & 1,5 \\
\hline 40 & 2,5 & 1,5 & 2,5 & 2 & 2 & 2,5 & 0 & 0 & 0 & 3 & 1,5 & 1 \\
\hline 41 & 2 & 0 & 0 & 0 & 0 & 0 & 0 & 0 & 0 & 2,5 & 0 & 0,5 \\
\hline 42 & 0 & 0 & 0 & 0 & 0 & 0 & 0 & 0 & 0 & 1,5 & 0 & 1 \\
\hline 43 & 0 & 0 & 0 & 0 & 0 & 0 & 0 & 0 & 0 & 2,5 & 1 & 2 \\
\hline 44 & 52,5 & 0 & 0 & 6,5 & 0 & 0 & 0 & 0 & 0 & 238 & 103 & 157 \\
\hline 45 & 1,5 & 0,5 & 0 & 0 & 0 & 0 & 0,5 & 0 & 0 & 4,5 & 2 & 2 \\
\hline 46 & 0 & 0 & 0 & 0 & 0 & 0 & 0 & 0 & 0 & 0 & 0 & 1 \\
\hline
\end{tabular}

${ }^{1}$ Stonebrink; ${ }^{2}$ Löwenstein-Jensen com piruvato; ${ }^{3}$ Middlebrook $7 \mathrm{H} 11 ;{ }^{4}$ Ágar sangue tuberculose; ${ }^{5}$ Atmosfera com $10 \%$ de CO2; ${ }^{6}$ Atmosfera ambiente;

${ }^{7}$ Algodão queimado; ${ }^{8}$ Incontável. 


\section{APÊNDICE D}

Número de UFC de Mycobacterium bovis aos 90 dias de incubação, segundo os meios de cultura e as condições de incubação.

\begin{tabular}{|c|c|c|c|c|c|c|c|c|c|c|c|c|}
\hline \multirow{4}{*}{ repetições } & \multicolumn{12}{|c|}{ meios de cultura } \\
\hline & \multicolumn{3}{|c|}{ Sto $^{1}$} & \multicolumn{3}{|c|}{$\mathrm{LJp}^{2}$} & \multicolumn{3}{|c|}{$7 \mathrm{H} 11^{3}$} & \multicolumn{3}{|c|}{$\mathrm{B}^{8} 3^{4}$} \\
\hline & \multicolumn{3}{|c|}{ condição de incubação } & \multicolumn{3}{|c|}{ condição de incubação } & \multicolumn{3}{|c|}{ condição de incubação } & \multicolumn{3}{|c|}{ condição de incubação } \\
\hline & $\mathrm{CO}_{2}{ }^{5}$ & $\mathrm{NOR}^{6}$ & $\mathrm{QUE}^{7}$ & $\mathrm{CO}_{2}$ & NOR & QUE & $\mathrm{CO}_{2}$ & NOR & QUE & $\mathrm{CO}_{2}$ & NOR & QUE \\
\hline 1 & 2 & 0 & 0 & 0 & 0 & 1 & 0 & 0 & 0 & 0 & 1 & 0 \\
\hline 2 & 0 & 0 & 0 & 0 & 1 & 0 & 0 & 0 & 0 & 0 & 0 & 0 \\
\hline 3 & 3 & 0 & 0 & incont $^{8}$ & 0 & 1 & 0 & 6 & 8 & 0 & 2 & 0 \\
\hline 4 & 0 & 0 & 0 & 0 & 1 & 0 & 0 & 0 & 0 & 0 & 0 & 0 \\
\hline 5 & 0 & 1 & 0 & 2 & 0 & 0 & 0 & 0 & 0 & 0 & 0 & 0 \\
\hline 6 & 0 & 1 & 2 & 1 & 0 & 1 & 2 & 0 & 0 & 1 & 1 & 0 \\
\hline 7 & 1 & 0 & 0 & 0 & 0 & 0 & 0 & 0 & 0 & 0 & 0 & 0 \\
\hline 8 & 4 & 3,5 & 5 & 5 & 3 & 3 & 3 & 2 & 2 & 14 & 2,5 & 1 \\
\hline 9 & 3 & 1 & 1 & incont & 2 & 1,5 & 0 & 3 & 2 & 3 & 2 & 1 \\
\hline 10 & 2,5 & 0 & 2 & 4,5 & 1 & 1,5 & 1 & 0 & 2 & incont & 1 & 3 \\
\hline 11 & 0 & 0 & 0 & 1 & 0 & 0 & 0 & 0 & 0 & 0 & 0 & 0 \\
\hline 12 & 1 & 0 & 0 & 0 & 1 & 0 & 0 & 9 & 0 & 0 & 1 & 0 \\
\hline 13 & 0 & 0 & 0 & 0 & 0 & 0 & 0 & 0 & 0 & 0 & 1 & 0 \\
\hline 14 & 4 & 3 & 0 & 5 & incont & 1 & 0 & 0 & 0 & 1 & 0 & 0 \\
\hline 15 & 0,5 & 0 & 1 & 0,5 & 0 & 0,5 & 0 & 0 & 0 & 0 & 0 & 0 \\
\hline 16 & 0 & incont & 0 & 0 & 이 & 0,5 & 0 & 0 & 0 & 0 & 0 & 0 \\
\hline 17 & 1 & 0,5 & 0 & 0 & 0 & 0,5 & 0 & 0 & 0 & 0 & 0 & 0 \\
\hline 18 & 0 & 0,5 & 0 & 1,5 & 0 & 0 & 0 & 0 & 0 & 0,5 & 0 & 0 \\
\hline 19 & 1 & incont & 2 & 2 & 0,5 & 1 & 0,5 & 0 & 0 & 1 & 4 & 0 \\
\hline 20 & 0 & 5 & 0 & 1,5 & incont & 0 & 0 & 0 & 0 & 1 & 1 & 0 \\
\hline 21 & 0,5 & 0,5 & 0,5 & 0 & 0,5 & 1 & 0 & 0 & 0 & 1 & 0,5 & 1 \\
\hline 22 & 0 & 0 & 0 & 0 & 0,5 & 0 & 0 & 0 & 0 & 0 & 0 & 0 \\
\hline 23 & 2 & 0 & 0,5 & 0,5 & 0 & 0,5 & 0 & 0 & 0 & 0 & 0 & 0 \\
\hline 24 & 43,5 & 24,5 & 35 & 42 & incont & 39 & 7 & 0 & 0 & 35,5 & 27,5 & 16 \\
\hline 25 & 3 & 5 & 1,5 & 2 & 0,5 & 0,5 & 1 & 1,5 & 0 & 7,5 & 6 & 1,5 \\
\hline 26 & 0 & 0 & 0 & 0,5 & 0 & 0,5 & 0 & 0 & 0 & 0 & 0 & 0 \\
\hline 27 & 0,5 & 1 & 0 & 1 & 0 & 0,5 & 0 & 0 & 0 & 0,5 & 0 & 0 \\
\hline 28 & 0 & 1 & 1,5 & 0 & 0,5 & 0,5 & 0,5 & 0 & 0 & 1,5 & 0,5 & 1,5 \\
\hline 29 & incont & 1 & 1 & 3 & 4 & 0,5 & 0 & 0 & 0 & 1,5 & 1 & 1 \\
\hline 30 & 4 & 0,5 & 1 & incont & 0,5 & 1,5 & 0 & 0 & 0 & 1 & 0,5 & 0 \\
\hline 31 & 0 & incont & 0 & 0 & 0 & 0 & 0 & 0 & 0 & 0 & 0 & 0 \\
\hline 32 & 0 & 0 & 0 & 0 & 0 & 0 & 0 & 0 & 0 & 1,5 & 0,5 & 0 \\
\hline 33 & 1 & 0 & 1 & 0 & 0,5 & 0,5 & 0 & 0 & 0 & 1 & 0,5 & 1 \\
\hline 34 & 12 & 5,5 & 7,5 & 10 & 9 & 9 & 2 & 20 & 0 & 7,5 & 5,5 & 4 \\
\hline 35 & 0,5 & 14 & 0 & 0 & 0 & 0 & 0 & 0 & 0 & 0,5 & 0,5 & 1 \\
\hline 36 & 1 & 0,5 & 0,5 & 0 & 이 & 0 & 0 & 0 & 0 & 1 & 0 & 1 \\
\hline 37 & 43,5 & 19 & 27 & 34,5 & 19,5 & 30,5 & 0,5 & 0 & 0 & 18,5 & 19 & 12,5 \\
\hline 38 & 0 & 0,5 & 1 & 1 & 1,5 & 1 & 0 & 0 & 0 & 1,5 & 0 & 1,5 \\
\hline 39 & 6 & 3,5 & 4 & 7 & 6 & 43,5 & 0,5 & 0 & 0 & 4 & 2 & 1,5 \\
\hline 40 & 2,5 & 1,5 & 2,5 & 2 & 5 & 2,5 & 0 & 0 & 0 & 3 & 1,5 & 1 \\
\hline 41 & 2 & 0 & 0 & 0 & 0 & 0 & 0 & 0 & 0 & 3 & 0,5 & 0,5 \\
\hline 42 & 0,5 & 0 & 0 & 0 & 0 & 0 & 0 & 0 & 0 & 1,5 & 0 & 1 \\
\hline 43 & 0 & 0 & 0 & 0 & 0 & 0 & 0 & 0 & 0 & 2,5 & 1 & 2 \\
\hline 44 & 60 & 0 & 0 & 12 & 0 & 0 & 0 & 0 & 0 & 240 & 109 & 165 \\
\hline 45 & 2 & 0,5 & 0,5 & 0 & 0 & 0 & 1 & 0 & 0 & 4,5 & 2 & 2 \\
\hline 46 & 0 & 0 & 0 & 0 & 이 & 0 & 이 & 이 & 0 & 0 & 0 & 1 \\
\hline
\end{tabular}

${ }^{1}$ Stonebrink; ${ }^{2}$ Löwenstein-Jensen com piruvato; ${ }^{3}$ Middlebrook $7 \mathrm{H} 11 ;{ }^{4}$ Ágar sangue tuberculose; ${ }^{5}$ Atmosfera com $10 \%$ de CO2; ${ }^{6}$ Atmosfera ambiente; ${ }^{7}$ Algodão queimado; ${ }^{8}$ Incontável. 


\section{APÊNDICE E}

Tempo em dias para o aparecimento da primeira colônia de Mycobacterium bovis, segundo os meios de cultura e as condições de incubação.

\begin{tabular}{|c|c|c|c|c|c|c|c|c|c|c|c|c|}
\hline \multirow{4}{*}{ repetições } & \multicolumn{12}{|c|}{ meios de cultura } \\
\hline & \multicolumn{3}{|c|}{ Sto $^{1}$} & \multicolumn{3}{|c|}{$\mathrm{LJp}^{2}$} & \multicolumn{3}{|c|}{$7 \mathrm{H} 11^{3}$} & \multicolumn{3}{|c|}{${\mathrm{B} 83^{4}}^{4}$} \\
\hline & \multicolumn{3}{|c|}{ condição de incubação } & \multicolumn{3}{|c|}{ condição de incubação } & \multicolumn{3}{|c|}{ condição de incubação } & \multicolumn{3}{|c|}{ condição de incubação } \\
\hline & $\mathrm{CO}_{2}{ }^{5}$ & $\mathrm{NOR}^{6}$ & $\mathrm{QUE}^{7}$ & $\mathrm{CO}_{2}$ & NOR & QUE & $\mathrm{CO}_{2}$ & NOR & QUE & $\mathrm{CO}_{2}$ & NOR & QUE \\
\hline 1 & 28 & $-{ }^{8}$ & - & - & - & 52 & - & - & - & - & 34 & - \\
\hline 2 & - & - & - & - & 31 & - & - & - & - & - & - & - \\
\hline 3 & 29 & - & - & 29 & - & 52 & - & 36 & 29 & - & 36 & - \\
\hline 4 & - & - & - & - & 36 & - & - & - & - & - & - & - \\
\hline 5 & - & 90 & - & 36 & - & - & - & - & - & - & - & - \\
\hline 6 & - & 29 & 29 & 50 & - & 57 & 29 & - & - & 29 & 36 & - \\
\hline 7 & 29 & - & - & - & - & - & - & - & - & - & - & - \\
\hline 8 & 22 & 50 & 29 & 22 & 50 & 43 & 29 & 29 & 29 & 29 & 29 & 29 \\
\hline 9 & 22 & 57 & 36 & 29 & 57 & 50 & - & 29 & 29 & 36 & 29 & 29 \\
\hline 10 & 22 & - & 43 & 29 & 50 & 43 & 29 & - & 29 & 29 & 29 & 29 \\
\hline 11 & - & - & - & 71 & - & - & - & - & - & - & - & - \\
\hline 12 & 29 & - & - & - & 57 & - & - & 29 & - & - & 57 & - \\
\hline 13 & - & - & - & - & - & - & - & - & - & - & 29 & - \\
\hline 14 & 18 & 30 & - & 28 & 42 & 49 & - & - & - & 42 & - & - \\
\hline 15 & 21 & - & 58 & 28 & - & 42 & - & - & - & - & - & - \\
\hline 16 & - & 30 & - & - & - & 60 & - & - & - & - & - & - \\
\hline 17 & 21 & 30 & - & - & - & 45 & - & - & - & - & - & - \\
\hline 18 & - & 45 & - & 28 & - & - & - & - & - & 28 & - & - \\
\hline 19 & 21 & 30 & 45 & 28 & 45 & 49 & 60 & - & - & 21 & 28 & - \\
\hline 20 & - & 30 & - & 28 & 45 & - & - & - & - & 28 & 30 & - \\
\hline 21 & 28 & 30 & 58 & - & 45 & 90 & - & - & - & 28 & 28 & 28 \\
\hline 22 & - & - & - & - & 45 & - & - & - & - & - & - & - \\
\hline 23 & 21 & - & 49 & 28 & - & 49 & - & - & - & - & - & - \\
\hline 24 & 18 & 35 & 30 & 21 & 42 & 42 & 30 & - & - & 18 & 28 & 28 \\
\hline 25 & 21 & 35 & 42 & 30 & 45 & 45 & 60 & 45 & - & 18 & 28 & 28 \\
\hline 26 & - & - & - & 41 & - & 44 & - & - & - & - & - & - \\
\hline 27 & 27 & 44 & - & 30 & - & 57 & - & - & - & 27 & - & - \\
\hline 28 & - & 41 & 41 & - & 90 & 48 & 57 & - & - & 27 & 30 & 27 \\
\hline 29 & 20 & 41 & 41 & 27 & 35 & 44 & - & - & - & 27 & 30 & 30 \\
\hline 30 & 20 & 41 & 44 & 20 & 48 & 41 & - & - & - & 30 & 30 & - \\
\hline 31 & - & 47 & - & - & - & - & - & - & - & - & - & - \\
\hline 32 & - & - & - & - & - & - & - & - & - & 28 & 30 & - \\
\hline 33 & 16 & - & 61 & - & 90 & 90 & - & - & - & 19 & 44 & 28 \\
\hline 34 & 19 & 41 & 44 & 28 & 44 & 41 & 41 & 44 & - & 19 & 28 & 28 \\
\hline 35 & 19 & 30 & - & - & - & - & - & - & - & 28 & 41 & 28 \\
\hline 36 & 28 & 30 & 90 & - & - & - & - & - & - & 19 & - & 21 \\
\hline 37 & 16 & 30 & 30 & 21 & 41 & 41 & 34 & - & - & 21 & 28 & 28 \\
\hline 38 & - & 90 & 44 & 28 & 44 & 44 & - & - & - & 28 & - & 28 \\
\hline 39 & 16 & 41 & 44 & 21 & 41 & 41 & 44 & - & - & 19 & 28 & 28 \\
\hline 40 & 16 & 41 & 41 & 28 & 44 & 44 & - & - & - & 19 & 41 & 28 \\
\hline 41 & 31 & - & - & - & - & - & - & - & - & 38 & 78 & 42 \\
\hline 42 & 78 & - & - & - & - & - & - & - & - & 35 & - & 31 \\
\hline 43 & - & - & - & - & - & - & - & - & - & 27 & 30 & 30 \\
\hline 44 & 27 & - & - & 51 & - & - & - & - & - & 27 & 27 & 27 \\
\hline 45 & 27 & 58 & 62 & - & - & - & 37 & - & - & 27 & 34 & 30 \\
\hline 46 & - & - & - & - & - & - & - & - & - & - & - & 30 \\
\hline
\end{tabular}

${ }^{1}$ Stonebrink; ${ }^{2}$ Löwenstein-Jensen com piruvato; ${ }^{3}$ Middlebrook $7 \mathrm{H} 11 ;{ }^{4}$ Ágar sangue tuberculose; ${ }^{5}$ Atmosfera com $10 \%$ de CO2; ${ }^{6}$ Atmosfera ambiente;

${ }^{7}$ Algodão queimado; ${ }^{8}$ Não houve crescimento. 


\section{ANEXO A}

Meio de Stonebrink:

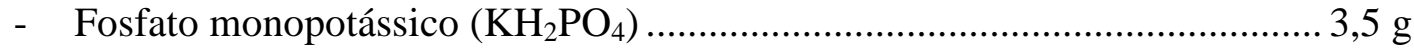

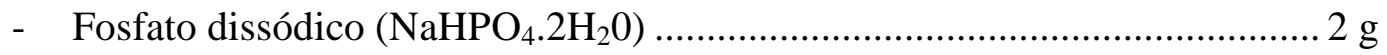

- Piruvato de sódio ............................................................................... 6, g

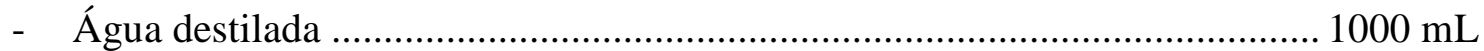

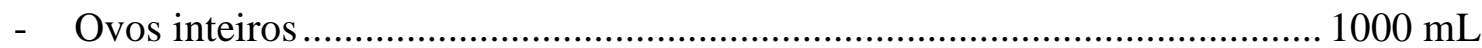

- Solução de Verde de Malaquita 2\% ….................................................... $20 \mathrm{~mL}$

Dissolver os sais na água destilada, esterilizar em autoclave durante 15 minutos a $120^{\circ} \mathrm{C}$ e deixar esfriar.

Lavar os ovos, que devem ser frescos, com água corrente e sabão, limpá-los com gaze embebida em álcool a 70\% e quebrá-los em um recipiente estéril até completar $1 \mathrm{~L}$.

Após bater os ovos com auxilio de um aparelho "mixer", misturá-los à solução salina e à solução de verde de malaquita a $2 \%$.

Filtrar em gaze estéril, distribuir e coagular em posição inclinada a $80^{\circ} \mathrm{C}$ por 30 minutos.

Obs: se for usado fosfato dissódico com 12 moléculas de $\mathrm{H}_{2} \mathrm{O}$, usar $4 \mathrm{~g}$.

Fonte: Centro Panamericano de Zoonosis (1985). 


\section{ANEXO B}

Meio de Löwenstein-Jensen com adição de Piruvato de Sódio:

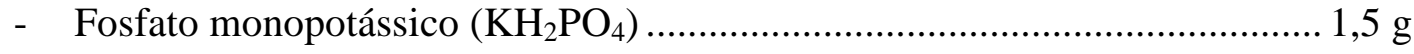

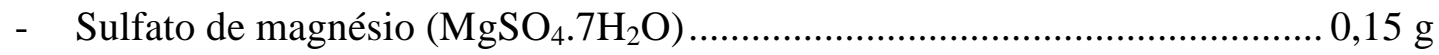

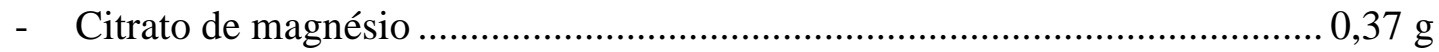

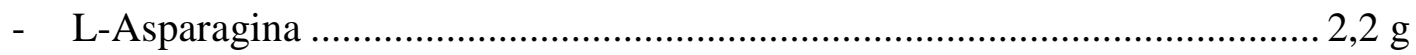

- Piruvato de sódio ................................................................................ $2 \mathrm{~g}$

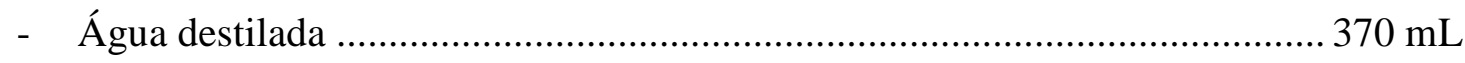

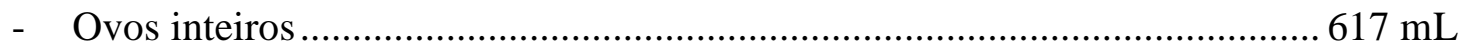

- Solução de Verde de Malaquita a 2\% ...................................................... 12 mL

Dissolver os sais e a asparagina em água destilada aquecida e esterilizar na autoclave a $120^{\circ} \mathrm{C}$ por 15 minutos.

Lavar os ovos com sabão e água. Deixá-los em álcool a 70\% por 30 minutos e secar por evaporação em uma superfície limpa.

Quebrar os ovos em um recipiente estéril e homogeneizar com auxilio de um aparelho "mixer".

Filtrar em gaze estéril em uma proveta até completar $617 \mathrm{~mL}$ e adicionar a solução salina e a solução de verde de malaquita a $2 \%$.

Distribuir e coagular em posição inclinada a $80^{\circ} \mathrm{C}$ por 30 minutos.

Fonte: Corner e Nicolacopoulos (1988). 


\section{ANEXO C}

Meio Agar Sangue Tuberculose ou B83:

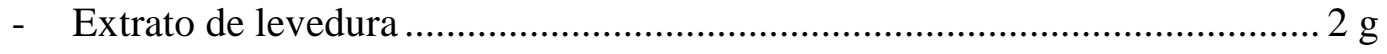

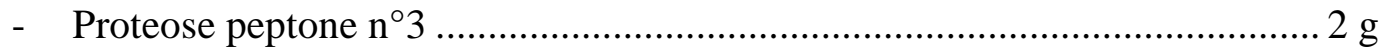

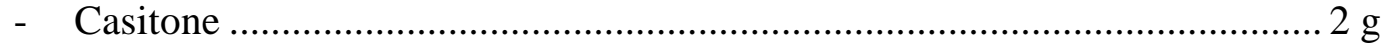

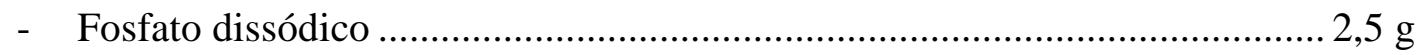

- Fosfato monopotássico ……............................................................... $1 \mathrm{~g}$

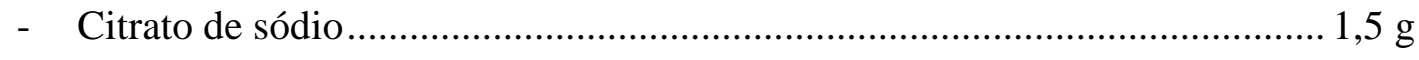

- Piruvato de sódio .............................................................................. $2 \mathrm{~g}$

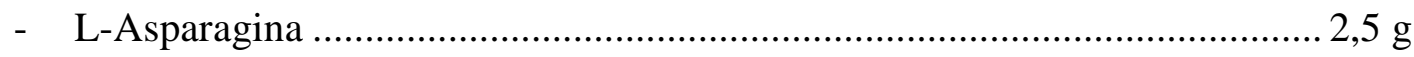

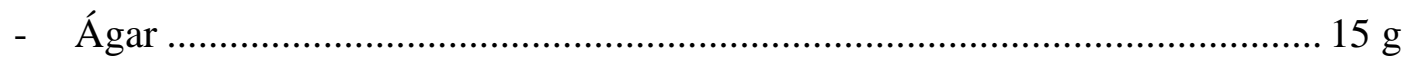

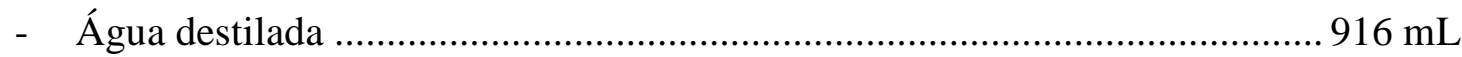

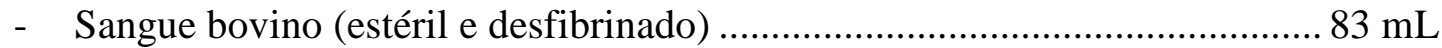

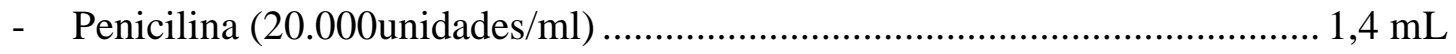

Preparar os reagentes com o ágar e a água destilada aquecendo no vapor por 30 minutos para dissolver e esterilizar na autoclave a $120^{\circ} \mathrm{C}$ por 20 minutos, em seguida deixar esfriar a $50^{\circ} \mathrm{C}$.

Adicionar assepticamente o sangue bovino e a penicilina.

Distribuir e armazenar a $4^{\circ} \mathrm{C}$.

Fonte: Corner e Nicolacopoulos (1988). 


\section{ANEXO D}

Meio de Middlebrook 7H11:

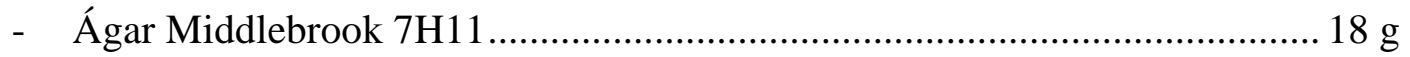

- Hidrolisado de caseína (digestão pancreática de caseína) ............................. $1 \mathrm{~g}$

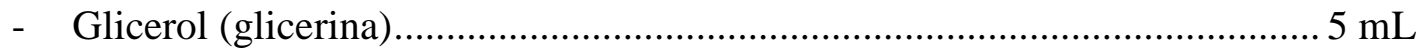

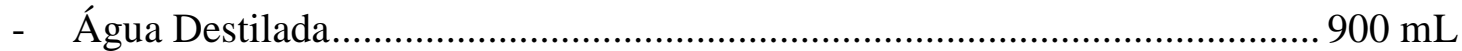

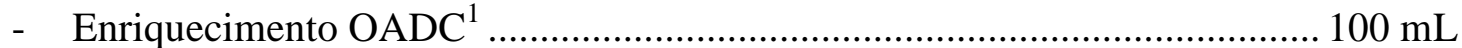

Adicionar o ágar, a caseína e o glicerol à água destilada agitando-os suavemente.

Esterilizar em autoclave a $121^{\circ} \mathrm{C}$ por 15 minutos e deixar esfriar a $56^{\circ} \mathrm{C}$ para adicionar assepticamente o enriquecimento à temperatura ambiente.

Homogeneizar com cuidado para evitar a formação de bolhas e distribuir, armazenando a $4^{\circ} \mathrm{C}$.

1) BBLtn Middlebrook OACD Enrichment - 13ecton Dickson Microbiology, Systems

Fonte: Cousins, Francis e Gow (1989). 


\section{ANEXO E}

Protocolo de extração e purificação de Ácido Desoxirribonucléico (DNA):

- retirar uma alçada da massa bacteriana;

- $\quad$ transferir para um microtubo de $1,5 \mathrm{~mL}$ com $400 \mu \mathrm{L}$ de tampão TE (10mM TRIS$\mathrm{HCl}$ e 1mM EDTA com $\mathrm{pH} 8,0)$;

- homogeneizar;

- $\quad$ incubar a $80^{\circ} \mathrm{C}$ por 20 minutos;

- $\quad$ adicionar $50 \mu \mathrm{L}$ de lisozima $(10 \mathrm{mg} / \mathrm{mL})$;

- homogeneizar;

- incubar a $37^{\circ} \mathrm{C}$ "overnight";

- $\quad$ adicionar $5 \mu \mathrm{L}$ de proteinase $\mathrm{K}(10 \mathrm{mg} / \mathrm{mL})$ e $70 \mu \mathrm{L}$ de SDS a $10 \%$;

- homogeneizar;

- $\quad$ incubar a $65^{\circ} \mathrm{C}$ por 10 minutos;

- $\quad$ adicionar $100 \mu \mathrm{L}$ de $5 \mathrm{M} \mathrm{NaCl}$;

- $\quad$ adicionar $100 \mu \mathrm{L}$ de $\mathrm{CTAB} / \mathrm{NaCl}$ pré-aquecida a $65^{\circ} \mathrm{C}$;

- homogeneizar;

- incubar a $65^{\circ} \mathrm{C}$ por 10 minutos;

- $\quad$ adicionar $750 \mu \mathrm{L}$ de clorofórmio:álcool isoamílico (24:1);

- homogeneizar;

- centrifugar a $12.000 \mathrm{G}$ por 7 minutos;

- $\quad$ transferir $450 \mu \mathrm{L}$ do sobrenadante para um tubo novo;

- $\quad$ adicionar $450 \mu \mathrm{L}$ de isopropanol (2-propanol);

- $\quad$ manter a $-20^{\circ} \mathrm{C}$ por 30 minutos;

- centrifugar a $12.000 \mathrm{G}$ por 15 minutos;

- desprezar sobrenadante;

- $\quad$ adicionar $1000 \mu \mathrm{L}$ de etanol $70 \%$ gelado;

- centrifugar a $12.000 \mathrm{G}$ por 5 minutos;

- desprezar sobrenadante;

- $\quad$ secar a $56^{\circ} \mathrm{C}$ por 10 minutos;

- $\quad$ ressuspender com $30 \mu \mathrm{L}$ de tampão TE;

- $\quad$ armazenar $\mathrm{a}-20^{\circ} \mathrm{C}$.

Fonte: adaptação de: Kremer et al. (1999) e Bemer-Melchior e Drugeon (1999). 


\section{ANEXO F}

Protocolo de PRA (Polymerase Chain Reaction Restriction Analysis):

Para um volume final de $50 \mu \mathrm{L}$, cada reação deve conter:

- $\quad 8,0 \mu \mathrm{L}$ de dNTP $1,25 \mathrm{mM}$;

- $\quad$ 5,0 $\mu \mathrm{L}$ de tampão 10x PCR Buffer (KCl 50mM; tris-HCl 10mM pH 8,3-9,0)

- $\quad 1,5 \mu \mathrm{L}$ de $\mathrm{MgCl}_{2} 50 \mathrm{mM}$;

- $\quad 0,3 \mu \mathrm{L}$ de Taq DNA polimerase platinum $5 \mathrm{U} / \mu \mathrm{L}$;

- $\quad 25,2 \mu \mathrm{L}$ de água ultra pura;

- $\quad 2,5 \mu \mathrm{L}$ do primer Tb11 (5'-ACCAACGATGGTGTGTCCAT-3') 10pmol/ $\mu \mathrm{L}$;

- $\quad 2,5 \mu \mathrm{L}$ do primer Tb12 (5'-CTTGTCGAACCGCATACCCT-3') 10pmol/ $\mu \mathrm{L}$;

- $\quad 5 \mu \mathrm{L}$ do DNA extraído.

A amplificação ocorre com 45 ciclos das seguintes temperaturas:

- $\quad 94^{\circ} \mathrm{C}$ por 1 minuto;

- $\quad 60^{\circ} \mathrm{C}$ por 1 minuto;

- $\quad 72^{\circ} \mathrm{C}$ por 1 minuto;

- 1 ciclo de extensão final de $72^{\circ} \mathrm{C}$ por 10 minutos.

Para a digestão do fragmento amplificado, cada reação tem volume final de $20 \mu \mathrm{L}$ : BstEII

- $\quad 0,5 \mu \mathrm{L}$ da enzima $B s t$ EII (5U);

- $\quad 0,2 \mu \mathrm{L}$ de BSA (soro albumina bovina);

- $\quad 2,0 \mu \mathrm{L}$ de D 10x Buffer;

- $\quad 7,3 \mu \mathrm{L}$ de água ultra pura;

- $\quad 10 \mu \mathrm{L}$ do produto amplificado;

- $\quad 60^{\circ} \mathrm{C}$ por 90 minutos.

HaeII

- $\quad 0,5 \mu \mathrm{L}$ da enzima HaeII (5U);

- $\quad 2 \mu \mathrm{L}$ de REact 2; 
- $\quad 7,5 \mu \mathrm{L}$ de água ultra pura;

- $\quad 10 \mu \mathrm{L}$ do produto amplificado;

- $\quad 37^{\circ} \mathrm{C}$ por 60 minutos.

Para visualizar o produto amplificado digerido por eletroforese:

- utilizar uma cuba horizontal com gel de agarose a 3\% imerso em tampão TrisBorato-EDTA (Tris-Borato 0,04M; EDTA 0,5mM);

- $\quad$ homogeneizar $10 \mu \mathrm{L}$ de cada amostra com $2 \mu \mathrm{L}$ de corante (30\% de glicerol : $0,25 \%$ de azul bromofenol);

- corar o gel em solução de brometo de etidio a $0,5 \mu \mathrm{g} / \mathrm{mL}$;

- $\quad$ visualizar em transluminador ultravioleta (UV);

Pode ser fotografado por um sistema de foto-documentação.

A interpretação do padrão de bandas é realizada através do site: www.app.chuv.ch/prasite.

Fonte: adaptação de: Telenti et al. (1993). 


\section{ANEXO G}

Protocolo de Spoligotyping:

Para um volume final de $50 \mu \mathrm{L}$, cada reação deve conter:

- $\quad 8,0 \mu \mathrm{L}$ de dNTP $1,25 \mathrm{mM}$;

- $\quad$ 5,0 $\mu \mathrm{L}$ de tampão 10x PCR Buffer (KCl 50mM; tris-HCl 10mM pH 8,3-9,0)

- $\quad 2,5 \mu \mathrm{L}$ de $\mathrm{MgCl}_{2} 50 \mathrm{mM}$;

- $\quad 0,25 \mu \mathrm{L}$ de Taq DNA polimerase platinum $5 \mathrm{U} / \mu \mathrm{L}$;

- $\quad 31,25 \mu \mathrm{L}$ de água ultra pura;

- $\quad 1,0 \mu \mathrm{L}$ do primer DRa (5'-GGGTTTGGGTCTGACGAC-3') $10 \mathrm{pmol} / \mu \mathrm{L}$;

- $\quad 1,0 \mu \mathrm{L}$ do primer DRb (5'-CCGAGAGGGGACGGAAAC-3') $10 \mathrm{pmol} / \mu \mathrm{L}$;

- $\quad$ 1,0 $\mu \mathrm{L}$ do DNA extraído (incluir M. tuberculosis H37Rv e M. bovis BCG como controles positivos, e água como controle negativo).

A amplificação ocorre com as seguintes temperaturas:

- desnaturação a $94^{\circ} \mathrm{C}$ por 3 minutos;

- $\quad 30$ vezes do ciclo:

- $\quad 94^{\circ} \mathrm{C}$ por 1 minuto;

- $\quad 55^{\circ} \mathrm{C}$ por 1 minuto;

- $\quad 72^{\circ} \mathrm{C}$ por 30 segundos;

- 1 ciclo de extensão final de $72^{\circ} \mathrm{C}$ por 7 minutos.

Hibridização e detecção:

- preparar as seguintes soluções e pré aquecê-las antes de usar:

- $\quad 2 x \mathrm{SSPE} / 0,1 \%$ de $\operatorname{SDS}$ a $42^{\circ} \mathrm{C}$;

- $\quad 2$ X SSPE $/ 0,5 \%$ de SDS a $60^{\circ} \mathrm{C}$;

- $\quad 2$ x SSPE $/ 0,5 \%$ de SDS a $42^{\circ} \mathrm{C}$;

- 2x SSPE a temperatura ambiente.

- $\quad$ adicionar $20 \mu \mathrm{L}$ do produto amplificado a $180 \mu \mathrm{L}$ de 2x SSPE/0,1\%SDS;

- desnaturar a $99^{\circ} \mathrm{C}$ por 15 minutos, em seguida resfriar em gelo imediatamente;

- lavar a membrana em $250 \mathrm{~mL}$ de 2 x SSPE/0,1\% de SDS a $42^{\circ} \mathrm{C}$ por 5 minutos; 
- ajustar a membrana e um suporte acolchoado no miniblotter de modo que as linhas de aplicação das sondas fiquem perpendiculares à aplicação das amostras;

- remover o fluido residual das linhas de aplicação por aspiração;

- $\quad$ preencher as linhas de aplicação com o produto amplificado diluído evitando bolhas de ar e hibridizar a $60^{\circ} \mathrm{C}$ por 60 minutos em superfície horizontal;

- remover as amostras do miniblotter por aspiração e retirar a membrana com auxilio de pinças;

- lavar duas vezes a membrana em $250 \mathrm{~mL}$ de 2 x SSPE/0,5\% de SDS a $60^{\circ} \mathrm{C}$ por 5 minutos;

- colocar a membrana em uma bolsa de hibridização e resfriar;

- adicionar $5 \mu \mathrm{L}$ de conjugado estreptovidina-peroxidase $(500 \mathrm{U} / \mathrm{mL})$ diluída em $14 \mathrm{~mL}$ de 2 x SSPE/0,5\% de SDS e incubar a $4^{\circ} \mathrm{C}$ por 60 minutos;

- lavar duas vezes a membrana em $250 \mathrm{~mL}$ de 2 x SSPE/0,5\% de SDS a $42^{\circ} \mathrm{C}$ por 10 minutos;

- enxaguar a membrana duas vezes em $250 \mathrm{~mL}$ de 2x SSPE em temperatura ambiente por 5 minutos;

- $\quad$ incubar a membrana por 2 minutos com $16 \mathrm{~mL}$ de reagentes de quimioluminescência $($ ECL $®$ Amersham Pharmacia);

- cobrir a membrana com uma folha plástica transparente e com um filme sensível à luz por 20 minutos.

- revelar o filme com reagentes para radiografia

Regeneração da membrana:

- lavar duas vezes a membrana em solução $1 \%$ de $\operatorname{SDS}$ a $80^{\circ} \mathrm{C}$ por 30 minutos;

- lavar a membrana em solução de $20 \mathrm{mM}$ de EDTA pH 8,0, a temperatura ambiente por 15 minutos;

- $\quad$ armazenar membrana a $4^{\circ} \mathrm{C}$.

Fonte: adaptação de: Spoligotyping ([200-?]). 